\title{
The Timing of Asset Trade and Optimal Policy in Dynamic Open Economies*
}

\author{
Ozge Senay ${ }^{\dagger}$ and Alan Sutherland ${ }^{\ddagger}$
}

September 2011

\footnotetext{
${ }^{*}$ We thank an anonymous referee and an associate editor for many useful comments on an earlier draft.

${ }^{\dagger}$ School of Economics and Finance, University of St Andrews, St Andrews, KY16 9AL, UK. E-mail: os12@st-andrews.ac.uk Tel: +44 1334462422 Fax: +44 1334462444

${ }^{\ddagger}$ School of Economics and Finance, University of St Andrews, St Andrews, KY16 9AL, UK and CEPR. E-mail: ajs10@st-andrews.ac.uk Tel: +44 1334462446 Fax: +44 1334462444
} 
Corresponding Author: Ozge Senay, University of St Andrews

Address: School of Economics and Finance, University of St Andrews, St Andrews, KY16 9AL, UK

E-mail: os12@st-andrews.ac.uk

Tel: +44 1334462422

Fax: +44 1334462444

Running Head: Asset Trade Timing and Monetary Policy 


\begin{abstract}
Using a standard open economy DSGE model, it is shown that the timing of asset trade relative to policy decisions has a potentially important impact on the welfare evaluation of monetary policy at the individual country level. If asset trade in the initial period takes place before the announcement of policy, a national policymaker can choose a policy rule which reduces the work effort of households in the policymaker's country in the knowledge that consumption is fully insured by optimally chosen international portfolio positions. But if asset trade takes place after the policy announcement, this insurance is absent and households in the policymaker's country bear the full consumption consequences of the chosen policy rule. The welfare incentives faced by national policymakers are very different between the two cases. Numerical examples confirm that asset market timing has a significant impact on the optimal policy rule.
\end{abstract}

Keywords: Asset trade; optimal monetary policy; monetary policy in open economies; international financial markets.

JEL: E52, F41 


\section{Introduction}

In the literature on optimal monetary policy in open economies it is common practice to model international asset markets in the form of trade in a complete set of Arrow-Debreu securities. ${ }^{1}$ This makes it possible to side-step explicit analysis of portfolio allocation problems. But new solution techniques (Devereux and Sutherland (2011) and Tille and van Wincoop (2010)) now make it possible to conduct a much more explicit analysis of asset market structure and its implications for optimal policy. These techniques can be used to consider explicitly the way in which asset markets affect the transmission mechanism between monetary policy and welfare. In this paper, we use these new techniques to examine in detail the role of the timing of asset trade relative to the timing of policy decisions in determining the way monetary policy affects welfare in an open economy.

We show that the incentives faced by a policymaker can be very different depending on whether asset trade takes place before or after monetary policy is determined. If asset trade takes place before policy is determined, equilibrium international portfolio positions provide a high degree of insurance against the effects of policy. This insurance is not present if asset trade takes place after policy is determined. In effect, if asset trade takes place before policy is determined, the insurance provided by asset portfolios creates an international spillover effect which implies that some of the negative welfare impact of policy in one country falls on foreign households. The insurance against the effect of policy, and thus the spillover effect, is absent when asset trade takes place after policy is determined. We show that the presence or absence of this insurance, and thus the presence or absence of the spillover effect, has a significant impact on the welfare maximising choice of monetary policy by national policymakers. ${ }^{2}$

One way to illustrate how asset market timing impinges on equilibrium in an open economy model is to note that in much of the existing literature it is typically stated that complete international risk sharing implies a relationship of the form $U_{C^{*}} / U_{C}=k Q$, where $U_{C}$ and $U_{C^{*}}$ are home and foreign marginal utilities of consumption, $Q$ is the real exchange rate and $k$ is a constant which is implicitly determined by equilibrium in asset 
markets. The asset-trade-before-policy case, which is the typical assumption in much of the existing literature, is consistent with an assumption that $k$ is exogenous and unrelated to policy choices. On the other hand, the asset-trade-after-policy case implies that $k$ is endogenous and depends on policy choices.

The general principles of these arguments are straightforward to describe and understand. The details of how these mechanisms operate within a fully specified dynamic stochastic general equilibrium model with international trade in multiple assets are, however, much less obvious. For instance, in a dynamic model where asset trade takes place period-by-period it appears that asset trade must inevitably take place after a policy change has been announced. Does this imply that asset markets do not provide insurance against policy changes?

This paper provides a systematic analysis of the links between policy decisions, consumption and welfare and shows explicitly how the timing of asset trade affects the incentives of the policymaker. We show that policy decisions affect consumption (and therefore welfare) via two asset market transmission channels. One is a flow effect which arises in periods subsequent to the policy change, while the other is a one-off capital gain effect which potentially arises in the period in which a policy change is announced.

The flow income effect is generated by a difference between home and foreign income. If, for instance, the home monetary authority follows a policy rule which tends to depress the expected level of home output, the flow income effect will, other things being equal, imply a reduction in home consumption. The capital gain effect, on the other hand, is the potential change in the value of the home country portfolio which occurs at the time monetary policy is announced (i.e. in the initial period). A fall in expected home income causes a fall in the value of home equity, which leads to a one-off capital gain for the home population in the initial period (because home households optimally hold a negative external position in home equity).

It is shown that the timing of asset trade in the initial period is critical in determining whether the capital gain effect is present or not. If asset trade in the initial period takes 
place before policy is determined then the capital gain effect is present. But if asset trade in the initial period takes place after policy is determined, the capital gain effect is absent. It is shown below that the presence or absence of this capital gain effect has an important impact on the incentives faced by the monetary policymaker. ${ }^{3}$

While there is now an extensive literature examining optimal monetary policy in open economy models, there has been no previous detailed analysis of the implications of assettrade timing for the welfare effects of policy in a dynamic multi-period setting. Indeed in much of the current literature (see e.g. Gali and Monacelli (2005), Benigno and Benigno (2006), Pappa (2004) and Faia and Monacelli (2008)) there is an implicit assumption that policy decisions are made after asset trade takes place in the initial period. There is rarely any justification for this assumption nor is there any recognition that it can have important implications for the welfare effects of monetary policy.

Senay and Sutherland (2007) do provide a basic analysis of asset market timing in a very simple static single-period model and merely state and demonstrate the general principle that asset market timing can affect optimal policy choices. ${ }^{4}$ Senay and Sutherland (2007) argued (but did not show explicitly) that monetary policy is likely to focus more on stabilisation of output and income when asset trade takes place after policy. This is because in the asset-trade-after-policy case the monetary authority anticipates that financial markets impose a welfare cost on a country when the monetary policy allows high output volatility. The current paper explicitly demonstrates this result, but goes much further by analysing asset market timing in a dynamic multiperiod framework. Arguably, asset market trade, and all matters related to the sequencing of events, can only adequately be addressed in such a setting.

In addition, the single-period model used in Senay and Sutherland (2007) lacks the complex dynamics that are integral to the standard workhorse models used in the international macro literature. As we show below, the extension of the basic single-period result to a dynamic setting is far from straightforward and one of the contributions of the current paper is therefore to show exactly how the timing of asset trade and the welfare 
effects of policy interact in a multi-period model of the type which is standard in the international macro literature.

In dynamic multi-period models with Arrow-Debreu asset trade, one can think about asset trade, and policy being set, in the initial time period. In such a framework, one way to approach the dynamic analogue of the Senay and Sutherland (2007) analysis would be to consider the timing of trade in Arrow-Debreu securities relative to the timing of policy within that initial period. However, in a more realistic dynamic setting, trade in realistic assets (such as bonds and equities) takes place period by period, rather than exclusively in the initial period. In this more realistic setting, it seems that asset trade will inevitably be taking place after policy decisions have been made.

This paper focuses on this more realistic setting and analyses the welfare effects of policy in a model with period-by-period trade in equity shares. Our analysis shows clearly that the question of the timing of asset trade relative to policy arises even when asset trade takes place period by period. The timing issue relates to the selection of an initial portfolio of asset holdings. It is this initial portfolio which determines the capital gain effect in the initial period. The fact that asset trade also takes place in all periods subsequent to the policy decision does not undermine the importance of the timing of asset trade in the initial period. ${ }^{5}$ This fact only becomes apparent in the dynamic framework analysed in this paper and this represents a further important contribution of the current paper relative to the static analysis in Senay and Sutherland (2007).

The current paper also goes further than Senay and Sutherland (2007) by explicitly modelling the equilibrium determination of asset market expectations of monetary policy. We show that in the asset-trade-before-policy case the anticipation of the policymaker's optimal policy decision affects asset prices in such a way that a welfare cost is imposed on households. This aspect of the asset-trade-before-policy case has not previously been analysed, so this represents a further contribution of the current paper relative to Senay and Sutherland (2007).

Before describing our analysis in detail, it is important to emphasise that we are 
not arguing that the modelling of asset market timing (relative to policy decisions) in itself represents a way to analyse market imperfections in international financial markets. What we are showing is that asset market timing has important logical implications for the interaction between financial markets and policy which have not been addressed in the existing literature. This issue arises in both complete markets and incomplete markets settings and can co-exist with many forms of asset market imperfection.

The analysis presented below is based on a simple two-country new-Keynesian model. Policy is represented in terms of a choice of a feedback parameter in a monetary policy targeting rule. This choice is made in the initial period. This simple framework provides clear analytical solutions and thus helps to establish the main underlying principles. The issues highlighted here are, however, applicable to a wide range of open economy macro models. ${ }^{6}$

The paper proceeds as follows: Section 2 presents the model structure; Section 3 discusses the general approach to solving the model; Section 4 analyses the impact of the timing of asset trade on the determination of consumption; Section 5 demonstrates the implications for the welfare effects of policy and describes the determination of prior beliefs about monetary policy in the asset-trade-before-policy case. Section 6 concludes the paper.

\section{Model structure}

The model is a standard open economy DSGE model of the type which has been widely used to analyse monetary policy in open economies (see for instance, Gali and Monacelli (2005) and Benigno and Benigno (2006)). The details of the specific model presented below are chosen for illustrative purposes only. The results emphasised in this paper, however, apply to a wide range of models.

The model consists of two countries, home and foreign, inhabited by a continuum of infinitely lived individual households which are both consumers and producers. House- 
holds consume a basket of differentiated, perishable goods of total measure unity. Home country households produce fraction $n$ of goods while foreign households produce the remaining $n^{*}=1-n$. Each individual household uses labour effort to produce a single good and is the monopoly supplier of that good. Nominal price inertia is modelled in the form of Calvo (1983) price setting.

Asset trade takes the form of trade in equity claims on home and foreign income. There is assumed to be only one source of random disturbances in the model, so trade in two equity claims allows full sharing of consumption risk arising from this single source of shocks.

We focus on monetary policy and welfare from the point of view of home country households. The foreign country's monetary stance is taken as given. The structure of the foreign economy is otherwise identical to the home country, so the model description focuses on the home country equations. Where foreign variables do arise, they are indicated with an asterisk.

\subsection{Households and the goods market}

Representative household $h$ in the home country has a utility function of the form:

$$
U_{t}(h)=E_{t}\left[\sum_{s=t}^{\infty} \beta^{s-t}\left(\frac{C_{s}^{1-\rho}(h)}{1-\rho}-\frac{K}{\mu} y_{s}^{\mu}(h)\right)\right]
$$

where $C$ is a consumption index defined across all home and foreign goods, $y(h)$ is the output of good $h$ and $E_{t}$ is the expectations operator conditional on time- $t$ information. $K, \rho$ and $\mu$ are positive constants and $0<\beta<1$.

The consumption index $C$ for home agents is given by:

$$
C=\left[\left(\frac{1}{2}\right)^{\frac{1}{\theta}} C_{H}^{\frac{\theta-1}{\theta}}+\left(\frac{1}{2}\right)^{\frac{1}{\theta}} C_{F}^{\frac{\theta-1}{\theta}}\right]^{\frac{\theta}{\theta-1}}
$$

where $\theta>0$ and $C_{H}$ and $C_{F}$ are indices of individual home and foreign produced goods 
with an elasticity of substitution between individual goods $\phi$, where $\phi>1$. The parameter $\theta$ is the elasticity of substitution between home and foreign goods. Home and foreign goods are assumed to have equal weight in the consumption basket. Combined with an assumption of producer currency pricing, this ensures that purchasing power parity holds in all states of the world. The aggregate consumer price index for home agents is:

$$
P=\left[\frac{1}{2} P_{H}^{1-\theta}+\frac{1}{2} P_{F}^{1-\theta}\right]^{\frac{1}{1-\theta}}
$$

where $P_{H}$ and $P_{F}$ are the aggregate price indices for home and foreign goods.

Goods prices are assumed to be set in the currency of the producer and are subject to Calvo (1983) price contracts. The probability that a given producer changes its price in any particular period is taken to be a constant, $(1-\gamma)$. The first-order condition for the choice of prices implies the following

$$
E_{t}\left\{\sum_{s=t}^{\infty}(\beta \gamma)^{s-t}\left[(\phi-1) \frac{p_{H, t} y_{t, s}}{C_{s}^{\rho} P_{s}}-A_{s} \phi K y_{t, s}^{\mu}\right]\right\}=0
$$

where $y_{t, s}$ is the period-s output of a home producer whose price was last set in period $t$. Prices are assumed to be subject to "cost-push" disturbances, $A$, where

$$
\log A_{t}=\zeta \log A_{t-1}+\varepsilon_{A, t}
$$

where $\varepsilon_{A}$ is symmetrically distributed over the interval $[-\varepsilon, \varepsilon]$ with $E\left[\varepsilon_{A}\right]=0$ and $\operatorname{Var}\left[\varepsilon_{A}\right]=\sigma_{A}^{2}$. Cost push disturbances are assumed to affect only home country pricing and are the only source of shocks in the model. Foreign producers are not subject to cost push disturbances.

\section{$2.2 \quad$ Asset markets}

International financial trade takes the form of trade in equity claims on the value of home and foreign aggregate output. Thus the home equity is a claim on $Y_{t}=y_{t} P_{H, t} / P_{t}$, while 
the foreign equity is a claim on $Y_{t}^{*}=y_{t}^{*} P_{F, t}^{*} / P_{t}^{*}$, where $y_{t}$ and $y_{t}^{*}$ are aggregate outputs of home and foreign goods. Equity trade takes place period by period. At the end of period $t$, home and foreign households allocate their net asset position across portfolios of the two equity assets. In period $t+1$, shocks are realised and output, goods prices, equity prices and equity pay-offs are determined. At the end of period $t+1$ equity trade is repeated and portfolios are reallocated and held into period $t+2$, and so on for each future period.

The real pay-off to a unit of the home equity purchased in period $t$ is defined to be $Y_{t+1}+Z_{t+1}$, where $Z_{t+1}$ is the real price of home equity in period $t+1$. Thus the gross real rate of return on the home equity is $r_{1, t+1}=\left(Y_{t+1}+Z_{t+1}\right) / Z_{t}$, and the gross real return on foreign equity is $r_{2, t+1}=\left(Y_{t+1}^{*}+Z_{t+1}^{*}\right) / Z_{t}^{*}$. The aggregate budget constraint of the home country can then be defined as follows

$$
\alpha_{1, t}+\alpha_{2, t}=\alpha_{1, t-1} r_{1 t}+\alpha_{2, t-1} r_{2 t}+Y_{t}-C_{t}
$$

where $\alpha_{1, t-1}$ and $\alpha_{2, t-1}$ represent the real external holdings of home and foreign equity, brought into period $t$ from the end of period $t-1 .^{7}$

It is useful to define $W_{t}=\alpha_{1, t}+\alpha_{2, t}$ to be the total net claims of home agents on the foreign country at the end of period $t$ (i.e. the net foreign assets, or NFA, of home agents). The budget constraint can then be re-written as

$$
W_{t}=r_{2, t} W_{t-1}+Y_{t}-C_{t}+\alpha_{1, t-1} r_{x, t}
$$

where

$$
r_{x, t}=r_{1, t}-r_{2, t}
$$

Here the foreign equity is used as a numeraire and $r_{x, t}$ measures the "excess return" on the home equity. Because $\alpha_{1, t}$ and $\alpha_{2, t}$ measure the external position of the home country 
in home and foreign equity, market clearing in asset markets implies

$$
n \alpha_{1, t}+n^{*} \alpha_{1, t}^{*}=0, \quad n \alpha_{2, t}+n^{*} \alpha_{2, t}^{*}=0
$$

To simplify notation, in what follows we will drop the subscript from $\alpha_{1, t}$ and simply refer

to $\alpha_{t}$. It should be understood, therefore, that $\alpha_{t}=\alpha_{1, t}=-\frac{n^{*}}{n} \alpha_{1, t}^{*}, \alpha_{2, t}=W_{t}-\alpha_{t}$ and $\alpha_{2, t}^{*}=W_{t}^{*}+\frac{n}{n^{*}} \alpha_{t}$.

Preferences and the structure of asset markets imply that optimal consumption choices satisfy the following Euler equation

$$
C_{t}^{-\rho}=\beta E_{t} C_{t+1}^{-\rho} r_{2, t+1}
$$

while optimal portfolio choices imply

$$
E_{t} C_{t+1}^{-\rho} r_{x, t+1}=0
$$

\subsection{Monetary policy and asset trade in period 0}

Monetary policy is modelled in the form of a targeting rule. The monetary authority in the home country is assumed to choose the monetary instrument (which is not modelled explicitly) in order to ensure that the following targeting relationship holds

$$
\log \frac{P_{H, t}}{P_{H, t-1}}+\delta \log A_{t}=0
$$

Thus the monetary authority follows a state-contingent inflation targeting policy where $\delta$ measures the degree to which producer-price inflation is allowed to vary in response to cost push shocks. The analysis below focuses on the welfare implications of the choice of $\delta$. For the purposes of explaining and illustrating the main points of this paper, the precise functional form of the policy rule is not a central issue. The key comparison which we analyse below is the difference in the optimal choice of $\delta$ between the asset-trade-before- 
policy case and the asset-trade-after-policy case. ${ }^{8}$

The foreign monetary authority is assumed to follow a similar targeting rule. In the foreign case, however, $\delta$ is assumed to be zero (i.e. the foreign monetary authority completely stabilises the foreign PPI inflation rate). The foreign rule is taken as exogenous and fixed and our analysis is focused on the policy problem of the home country.

In the initial period (i.e. period 0), it is assumed that the only events that occur are:

- A once-and-for-all decision by the home policymaker about $\delta$, which is immediately announced publicly.

- International trade in equities to establish portfolio allocations to be carried into period 1.

The aim of the paper is to investigate the implication of the timing of asset trade in period 0 relative to the timing of the policymaker's decision about $\delta$. There are two alternative assumptions: (1) asset trade before policy; or (2) asset trade after policy.

We assume that households enter period 0 with zero net foreign assets and zero gross asset positions. Asset trade allows households to establish optimal gross portfolio positions which hedge against future shocks to $A$.

The crucial difference between the asset-trade-before-policy case and the asset-tradeafter-policy case is that households' knowledge of $\delta$ at the time of asset trade differs between the two cases. This is illustrated in the time-lines shown in Figures 1 and 2 .

\section{INSERT FIGURES 1 AND 2 ABOUT HERE}

Figure 1 shows that, in the case where asset trade in period 0 takes place before the policymaker determines $\delta$, households will trade assets in period 0 at prices which are determined before the true value of $\delta$ is known. Asset prices at the time of asset trade in period 0 will therefore incorporate household expectations of $\delta$, i.e. asset prices will be determined by their prior beliefs about $\delta$, which we denote $\delta^{T}$.

Figure 2 shows that, in the case where asset trade in period 0 takes place after the policymaker determines $\delta$, households will trade assets in period 0 at prices which are 
determined after $\delta$ is chosen. These asset prices will therefore incorporate full information on the true value of $\delta$.

In the case of asset trade before policy it is obviously necessary to specify how expectations of $\delta$ are formed. We will assume that agents in asset markets anticipate that $\delta$ is chosen by the home monetary authority to maximise home aggregate utility. The details of the determination of $\delta^{T}$ will be confirmed in Section 5 below, but at this stage the equilibrium choice of $\delta^{T}$ can usefully be illustrated via Figure 3. In this figure the value of $\delta^{T}$ is measured on the horizontal axis and the monetary authority's choice of $\delta$ is measured on the vertical axis. For each possible choice of $\delta^{T}$ it is possible to plot the monetary authority's "best response" in terms of the welfare maximising choice of $\delta$. An example of this "best response function" is illustrated in the figure. It will be shown below that the welfare maximising choice of $\delta$ is in fact independent of $\delta^{T}$, so the best response function is horizontal. The rational expectations equilibrium is where the best response function crosses the $45^{0}$ line, i.e. where the actual value of $\delta$ equals the expected value of $\delta$. This is labelled $B$ in the figure.

\section{INSERT FIGURE 3 ABOUT HERE}

Notice that, at the point of equilibrium, it is true by definition that the announcement of the actual value of $\delta$ does not create a surprise for asset markets. But also notice that to understand the incentives which support this equilibrium it is necessary to consider what happens to asset prices in out-of-equilibrium situations. Consider for instance a case where asset markets expect $\delta$ to be $\delta^{O}$, but where the monetary authority chooses a value of $\delta$ greater than $\delta^{O}$. Because asset trade in period 0 is based on asset prices which incorporate expectations $\delta^{O}$, and asset prices at the start of period 1 incorporate information on the true value of $\delta$, there will be a capital gain (or loss) induced by the announcement of monetary policy. This capital gain affects the NFA position of home households at the start of period 1 and thus affects consumption plans and welfare from period 1 onwards. A choice of $\delta$ less than $\delta^{O}$ would likewise generate a capital gain or loss which would have an impact on consumption plans and welfare. Thus, in general, the 
first-order condition for the welfare maximising choice of $\delta$ depends on the derivative of the capital gain with respect to $\delta$. Hence the incentives faced by the monetary authority when choosing $\delta$ are altered by the potential capital gain even though the capital gain itself is zero in equilibrium.

This can be contrasted with the asset trade after policy case. In this case none of the above capital gain effects arise because, when asset trade in period 0 takes place after $\delta$ is determined, asset prices always incorporate full information on $\delta$. There is thus no potential capital gain or loss generated by the announcement of policy. The absence of the capital gain term implies that policy will have a different effect on consumption and welfare compared to the asset-trade-before-policy case. The incentives faced by the monetary authority and the resulting optimal choice of $\delta$ will therefore also differ compared to the asset-trade-before-policy case. ${ }^{9}$

One way to interpret events in period 0 is in terms of a Stackelberg leader-follower game. In the asset-trade-before-policy case the asset market acts as the Stackelberg leader and the policymaker is the follower. In the asset-trade-after-policy case the roles are reversed, the policymaker is the leader and the asset market is the follower. In each case the follower is able to make optimal decisions in the light of the decisions made by the leader. ${ }^{10}$

\section{Model solution}

The aim of this paper is to investigate the implications of the timing of asset trade for the evaluation of home welfare in period 0 , i.e. welfare at the time that the policymaker makes a decision about the policy parameter, $\delta$. The main focus of analysis is therefore on the effects of the timing of asset trade on the incentives faced by the home-country policymaker. The analysis presented below proceeds first (in this section) by showing how expected portfolio returns affect the welfare of home agents. In Section 4 we then show how the timing of asset trade affects the link between policy decisions and expected 
portfolio returns. Section 5 then shows how the timing of asset trade affects the welfare incentives faced by the home policymaker. It turns out that these incentives are unrelated to the prior beliefs of agents regarding the policy parameter, $\delta$. The analysis presented in Sections 3 and 4 can proceed on the assumption that these prior beliefs are fixed and exogenous. However, as already indicated above, the analysis of the full equilibrium of the model in the asset-trade-before-policy case requires the solution for these prior beliefs. In Section 5 we complete the analysis by deriving the solution for the full equilibrium (including the endogenous determination of prior beliefs regarding $\delta$ ).

In models of the form outlined above, welfare analysis is typically based on a secondorder approximate solution for aggregate utility. Aggregate (per capita) home welfare in period 0 is given by

$$
\Omega=\frac{1}{n} E_{0} \sum_{s=0}^{\infty} \beta^{s}\left\{\int_{0}^{n}\left(\frac{C_{s}^{1-\rho}(h)}{1-\rho}-\frac{K}{\mu} y_{s}^{\mu}(h)\right) d h\right\}
$$

A second-order approximation of $\Omega$ can be written as follows

$$
\begin{aligned}
& \hat{\Omega}=(1-\beta) E_{0} \sum_{s=0}^{\infty} \beta^{s}\left\{\hat{C}_{s}+\frac{1}{2}(1-\rho) \hat{C}_{s}^{2}\right. \\
& \left.-\frac{\phi-1}{\phi}\left[\hat{y}_{s}+\frac{1}{2} \mu \hat{y}_{s}^{2}+\frac{1}{2} \frac{\phi \gamma(1-\phi+\phi \mu)}{(1-\gamma)(1-\beta \gamma)} \pi_{s}^{2}\right]\right\}+O\left(\varepsilon^{3}\right)
\end{aligned}
$$

where $O\left(\varepsilon^{3}\right)$ contains terms of order higher than two in the variables of the model, ${ }^{11}$ and $\pi_{s}=\hat{P}_{H, s}-\hat{P}_{H, s-1}$.

Equation (13) shows that home welfare depends on the first and second moments of consumption, output and the rate of producer price inflation (as measured by $\pi$ ). In the literature on optimal monetary policy there has been much discussion and analysis of the properties of welfare functions of this form. This analysis is now very standard and need not be repeated here. For the purposes of the current paper the main point that should be noted is that home welfare depends positively on the first moment of home consumption and negatively on the first moment of home output, i.e. positively on $E_{0}\left[\hat{C}_{s}\right]$ 
and negatively on $E_{0}\left[\hat{y}_{s}\right]$ for $s=1 . . . . \infty$.

In general, the policy parameter, $\delta$, affects the way the monetary instrument responds to shocks and therefore affects the second moments of the endogenous variables of the model. In turn, second moments affect first moments of variables at the level of a secondorder approximation. So, for instance, $\delta$ affects the risk premium on home equity (i.e. the expected return differential between home and foreign equity) and also, via the impact of risk on labour supply, $\delta$ affects the expected level of output. ${ }^{12}$ The precise nature of the links between $\delta$ and these variables is not the central issue in our analysis. It is sufficient to note that the policy parameter affects the expected level of output. The main question of concern in our analysis is how the timing of asset trade affects the link between the expected level of output and the expected level of consumption.

Equation (13) shows that a reduction in the expected level of home output directly increases home welfare (because it represents a reduction in work effort for home households). The overall welfare impact of a fall in home output, however, depends on how home consumption is affected by the consequent fall in home income. Asset markets impinge on the linkage between income and consumption via the impact of asset trade on the cross-country sharing of consumption risk. The first step in our analysis of asset market timing is therefore to derive a second-order approximation of the relationship between income, portfolio returns and consumption. This is based on a second-order approximation of aggregate budget constraints.

A second-order approximation for the aggregate home budget constraint is given by

$$
\hat{W}_{t}=\frac{1}{\beta} \hat{W}_{t-1}+\hat{Y}_{t}-\hat{C}_{t}+\tilde{\alpha} \hat{r}_{x, t}+\lambda_{B, t}+O\left(\varepsilon^{3}\right)
$$

where for convenience the second-order terms have been gathered together in the term $\lambda_{B, t}$ which is defined in the Appendix. In general, a bar over a variable indicates its value in the non-stochastic steady state and a hat indicates the log-deviation from the non-stochastic steady state, except for $\hat{W}_{t}=\left(W_{t}-\bar{W}\right) / \bar{C}, \tilde{\alpha}=\bar{\alpha} /(\beta \bar{Y}), \hat{r}_{1, t}=\beta\left(r_{1, t}-\bar{r}_{1}\right)$, $\hat{r}_{2, t}=\beta\left(r_{2, t}-\bar{r}_{2}\right)$ and $\hat{r}_{x, t}=\hat{r}_{1, t}-\hat{r}_{2, t}$. 
Notice that it is necessary to derive a solution for the gross portfolio position in the non-stochastic steady state, $\tilde{\alpha}$. For the above model, the solution method described by Devereux and Sutherland (2011) yields the following result ${ }^{13}$

$$
\tilde{\alpha}=-\frac{n^{*}}{1-\beta}
$$

This implies that the home country holds a negative external position in home equity and a positive external position in foreign equity. The intuition for this is obvious - optimal risk sharing is achieved by holding a diversified portfolio of claims on home income and foreign income. This is achieved by holding a negative external position in home equity and a corresponding positive external position in foreign equity. Foreign households hold the mirror-image portfolio.

Note that, in principle, the portfolio in period 0 may depend on the timing of asset trade, i.e. $\tilde{\alpha}$ in period 0 may differ from $\tilde{\alpha}$ in all subsequent periods. However, in this model the steady state portfolio is given by (15) in all periods (including period 0) regardless of the timing of asset trade.

We are interested in the evaluation of welfare at the time policy is determined in period 0 , so the focus of the analysis is on the expectation of $\hat{C}$ at the time of the policy decision, i.e. $E_{0}\left[\hat{C}_{t}\right]$, where $E_{0}$ denotes expectation conditional on information at the time of the policy decision. It is useful to decompose $\hat{C}_{t}$ as follows

$$
\hat{C}_{t}=n \hat{C}_{t}+n^{*} \hat{C}_{t}^{*}+n^{*} \hat{C}_{t}^{D}
$$

where $\hat{C}_{t}^{D}=\hat{C}_{t}-\hat{C}_{t}^{*}$. By definition total world real income equals total world real consumption, so it follows that (to a second order approximation)

$$
n \hat{C}_{t}+n^{*} \hat{C}_{t}^{*}=n \hat{Y}_{t}+n^{*} \hat{Y}_{t}^{*}+\lambda_{Y, t}+O\left(\varepsilon^{3}\right)
$$


where $\lambda_{Y, t}$ is a second-order term defined in the Appendix, so

$$
E_{0}\left[\hat{C}_{t}\right]=E_{0}\left[n \hat{Y}_{t}+n^{*} \hat{Y}_{t}^{*}+\lambda_{Y, t}+n^{*} \hat{C}_{t}^{D}\right]+O\left(\varepsilon^{3}\right)
$$

This provides part of the relationship between home-country consumption and homecountry income. The next step is to derive an expression for $E_{0}\left[\hat{C}_{t}^{D}\right]$.

This is relatively straightforward because the consumption Euler equation (9), and its foreign counterpart, imply that $E_{0}\left[\hat{C}_{t}^{D}\right]$ is equal to a constant for period 1 onwards i.e.

$$
E_{0}\left[\hat{C}_{t}^{D}\right]=E_{0}\left[\hat{C}_{1}^{D}\right] \text { for all } t>1
$$

so it is only necessary to derive an expression for $E_{0}\left[\hat{C}_{1}^{D}\right]$. Using the home budget constraint (14), its foreign counterpart, the usual transversality condition, equation (18) and $\hat{W}_{0}=0$, the following is derived

$$
\begin{aligned}
E_{0}\left[\hat{C}_{1}^{D}\right]= & (1-\beta) E_{0}\left[\hat{Y}_{1}-\hat{Y}_{1}^{*}+\frac{1}{n^{*}} \tilde{\alpha} \hat{r}_{x, 1}+\lambda_{A, 1}\right] \\
& +(1-\beta) \sum_{t=2}^{\infty} \beta^{t-1} E_{0}\left[\hat{Y}_{t}-\hat{Y}_{t}^{*}+\frac{1}{n^{*}} \tilde{\alpha} \hat{r}_{x, t}+\lambda_{A, t}\right]+O\left(\varepsilon^{3}\right)
\end{aligned}
$$

where $\lambda_{A, t}$ is a second-order term which is defined in the Appendix. This expression shows that $E_{0}\left[\hat{C}_{1}^{D}\right]$ is equal to the sum of the discounted value of expected future income differences, $\hat{Y}_{t}-\hat{Y}_{t}^{*}$, and portfolio returns, $\tilde{\alpha} \hat{r}_{x, t}$, (and the second-order term, $\lambda_{A, t}$ ). For convenience, this expression separates out the impact of income and portfolio returns in period 1 from the impact of the same variables in future periods. The portfolio return in period 1, $\tilde{\alpha} \hat{r}_{x, 1}$, depends on the timing of asset trade in period 0 , whereas the portfolio return from period 2 onwards, $\tilde{\alpha} \hat{r}_{x, t}$ for $t>1$, does not depend on the timing of asset trade. It is therefore useful to treat these two terms separately.

The combination of equations (17) and (19) can now be used to analyse the impact of asset market timing on the determination of home-country consumption. 


\section{The timing of asset trade, portfolio returns and consumption}

This section describes in detail the determination of portfolio returns. First, the expected portfolio return for period 2 onwards is derived. We then analyse portfolio returns in period 1. Because period 1 portfolio returns depend on the timing of asset trade, we consider separately the asset-trade-after-policy and asset-trade-before-policy cases.

\subsection{Portfolio returns for period 2 onwards}

In each period from period 2 onwards, optimal portfolio allocation and asset market clearing imply that the expected excess return is given by

$$
E_{t}\left[\hat{r}_{x, t+1}\right]=\frac{\rho}{2} E_{t}\left[\left(\hat{C}_{t+1}+\hat{C}_{t+1}^{*}\right) \hat{r}_{x, t+1}\right]+O\left(\varepsilon^{3}\right)
$$

This is the risk premium on home equity. ${ }^{14}$ This expression shows that the risk premium, up to a second order approximation, depends on one-period ahead conditional second moments, which are constant by assumption, so $E_{t}\left[\hat{r}_{x, t+1}\right]$ is a constant for $t>1$. It is useful to define $R \equiv \frac{\rho}{2} E_{t}\left[\left(\hat{C}_{t+1}+\hat{C}_{t+1}^{*}\right) \hat{r}_{x, t+1}\right]$. The law of iterated expectations implies $E_{0}\left[\hat{r}_{x, t+1}\right]=E_{t}\left[\hat{r}_{x, t+1}\right]=R+O\left(\varepsilon^{3}\right)$ for all $t>1$.

\subsection{Asset trade after policy}

The expected excess return in period 1 depends on whether asset trade in period 0 takes place before or after policy is determined. If asset trade takes place after policy is determined, asset prices in period 0 are determined with full knowledge of the true value of $\delta$. So the expected excess return between period 0 and period 1 is simply given by equation (20), i.e. $E_{0}\left[\hat{r}_{x, 1}\right]=R+O\left(\varepsilon^{3}\right)$ where $E_{0}$ and, thus $R$, is based on full knowledge of the true value of $\delta$.

Substituting using $E_{0}\left[\hat{r}_{x, t+1}\right]=R+O\left(\varepsilon^{3}\right)$ for $t \geq 1$ in (19) yields (after much simpli- 
fication) the following

$$
E_{0}\left[\hat{C}_{1}^{D}\right]=V+O\left(\varepsilon^{3}\right)
$$

where

$$
V=(1-\beta) \sum_{t=1}^{\infty} \beta^{t-1}\left(E_{0}\left[\hat{Y}_{t}-\hat{Y}_{t}^{*}\right]+\lambda_{V, t}\right)
$$

The Appendix provides a more detailed derivation of these expressions and defines the second-order term $\lambda_{V, t}$.

Equations (21) and (22) show how policy affects $E_{0}\left[\hat{C}_{1}^{D}\right]$ in the asset-trade-after-policy case. The value of $\delta$ can affect $V$ via its impact on the expected level of home income (relative to foreign income), $\left(\hat{Y}_{t}-\hat{Y}_{t}^{*}\right)$, or its impact on the second moments of home and foreign income via $\lambda_{V, t}$. Thus a policy which raises home country income relative to foreign country income will tend to raise home consumption relative to foreign consumption. This effect can be thought of as capturing the on-going "flow income effect" of policy on the sustainable level of home consumption.

To see the impact on home welfare it is necessary to consider the impact on the discounted present value of home consumption. Equation (17) can be used to derive the following

$$
\sum_{t=1}^{\infty} \beta^{t-1} E_{0}\left[\hat{C}_{t}\right]=\sum_{t=1}^{\infty} \beta^{t-1} E_{0}\left[\hat{Y}_{t}+\lambda_{C, t}\right]+O\left(\varepsilon^{3}\right)
$$

where $\lambda_{C, t}$ is a second-order term which is defined in the Appendix. Equation (23) shows the link between home income and home consumption in the asset-trade-after-policy case. An important feature of this relationship is that any change in the discounted value of home income has a one-for-one impact on the discounted value of home consumption. Thus, in the asset-trade-after-policy case, any policy change which reduces the discounted value of home income will reduce the discounted value of home consumption by an equivalent amount. It is now necessary to derive a relationship corresponding to equation (23) for the asset-trade-before-policy case. 


\subsection{Asset trade before policy}

It will now be shown that, if asset trade takes place before policy is determined, there is a potential capital gain or loss caused by the policy announcement which must be added to expected asset returns in period 1. This capital gain or loss is only non-zero in out-of-equilibrium situations where the announced value of $\delta$ differs from the value of $\delta$ expected at the time of asset trade. However, it will become apparent below that this potential capital gain or loss changes the first derivative of welfare with respect to the policy parameter $\delta$ and thus affects the incentives faced by the policymaker.

The simplest way to calculate the size and effect of the capital gain is to examine what would happen to asset prices if asset markets were hypothetically to re-open just after the policy announcement. The fact that the policy announcement has occurred by this stage obviously implies that asset prices will adjust to incorporate the new information on the policy parameter, $\delta$. The total expected excess return between the time of initial asset trade (i.e. before the policy announcement) and the start of period 1 can thus be decomposed into two parts. The first part is given by the capital gain (call this $C G$ ) caused by the change in asset prices between the time of initial asset trade and the time of the policy announcement. The second part is the expected excess return between the time of the policy announcement and the start of period $1 .{ }^{15}$

To derive the capital gain, $C G$, define $\hat{Z}_{0}^{* T}$ and $\hat{Z}_{0}^{T}$ to be equity prices at the initial

time of asset trade in period 0 and $\hat{Z}_{0}$ and $\hat{Z}_{0}^{*}$ to be equity prices in period 0 immediately after the announcement of policy. The excess capital gain (i.e. the difference between the capital gain on the two assets) is thus $C G=\left(\hat{Z}_{0}-\hat{Z}_{0}^{T}\right)-\left(\hat{Z}_{0}^{*}-\hat{Z}_{0}^{* T}\right)$. This captures the component of the excess return caused by the policy announcement.

Now consider the expected excess return between the time of the policy announcement and the start of period 1. At this time, because the value of the policy parameter is known, it must be the case that expected excess returns are determined in exactly the same way as in the asset-trade-after-policy case. In other words the expected excess return between the time of the policy announcement at the start of period 1 will be $R$, where 
$R=\frac{\rho}{2} E_{0}\left[\left(\hat{C}_{1}+\hat{C}_{1}^{*}\right) \hat{r}_{x, 1}\right]$ and $E_{0}$ is based on full knowledge of the true value of $\delta$.

The total expected excess return at the time of the policy announcement on assets held between the time of initial asset trade (i.e. before the policy announcement) and the start of period 1 is given by

$$
E_{0}\left[\hat{r}_{x, 1}\right]=C G+R+O\left(\varepsilon^{3}\right)
$$

This expression captures the effect of the policy announcement on expected portfolio returns at the time the policymaker makes an announcement about $\delta$. This is relevant for policymaker's assessment of the welfare effect of policy at the time the policy decision is made.

The link between the capital gain effect, $C G$, and consumption possibilities can be seen by substituting (24) and $E_{0}\left[\hat{r}_{x, t+1}\right]=R+O\left(\varepsilon^{3}\right)$ for $t \geq 1$ into (19) and simplifying to yield

$$
E_{0}\left[\hat{C}_{1}^{D}\right]=\frac{1}{n^{*}}(1-\beta) \tilde{\alpha} C G+V+O\left(\varepsilon^{3}\right)
$$

This can be contrasted with (21), which is the corresponding equation in the asset-tradeafter-policy case. The comparison between these two equations shows clearly the different ways policy will affect $E_{0}\left[\hat{C}_{1}^{D}\right]$ in the two cases. Equation (21) shows that, in the assettrade-after-policy case, policy will only affect $E_{0}\left[\hat{C}_{1}^{D}\right]$ via the impact of policy on $V$ (where $V$ is defined in (22)). Equation (25) shows that these effects will also arise in the assettrade-before-policy case, but in this case policy will have an additional effect on $E_{0}\left[\hat{C}_{1}^{D}\right]$ via the impact of policy on the capital gain term, $C G$.

Note again that the capital gain term is only non-zero for out-of-equilibrium choices of $\delta$. In equilibrium $C G$ is by definition zero. But at the time policy is determined, the incentives faced by the policymaker in the choice of $\delta$ are influenced by the capital gain or loss that would occur if the policymaker were to choose a non-equilibrium value of $\delta$.

The Appendix shows how an expression for $C G$ can be derived. This expression can 
be substituted into (25) and, after further algebra, it can be shown that

$$
E_{0}\left[\hat{C}_{1}^{D}\right]=V^{T}+O\left(\varepsilon^{3}\right)
$$

where

$$
V^{T}=(1-\beta) \sum_{t=1}^{\infty} \beta^{t-1}\left(E_{0}^{T}\left[\hat{Y}_{t}-\hat{Y}_{t}^{*}\right]+\lambda_{V, t}^{T}\right)
$$

where $E_{0}^{T}$ is the expectations operator based on households' prior belief about the value of $\delta$. The second-order term $\lambda_{V, t}^{T}$ is defined in the Appendix.

Note that $V^{T}$ in (27) is entirely determined by prior beliefs about $\delta$. This term is therefore (at the time policy is chosen) exogenous and independent from the true value of $\delta$. Equation (26) therefore shows that policy (in terms of the true value of $\delta$ ) cannot affect $E_{0}\left[\hat{C}_{1}^{D}\right]$ in the case where asset trade takes place before policy is determined. The underlying explanation for this result is revealed by comparing equations (25) and (26). These equations demonstrate that the impact of any unanticipated change in $\delta$ on $V$ is precisely offset by the impact of the change in $\delta$ on $C G$ such that $E_{0}\left[\hat{C}_{1}^{D}\right]$ is unaffected by $\delta$. In other words any deviation of $\delta$ from its expected value generates a one-off capital gain which exactly offsets the flow income effect of the policy deviation which operates through the future impact of policy on home income. ${ }^{16}$

The key implication of equation (27) is that the first derivative of $E_{0}\left[\hat{C}_{1}^{D}\right]$ with respect to $\delta$ is zero. The presence of the capital gain term in the asset-trade-before-policy case thus has a key role in determining the incentives faced by the monetary authority in the choice of $\delta$.

Equation (26) can now be used to derive the following expression for the discounted value of home consumption

$$
\sum_{t=1}^{\infty} \beta^{t-1} E_{0}\left[\hat{C}_{t}\right]=\sum_{t=1}^{\infty} \beta^{t-1} E_{0}\left[n \hat{Y}_{t}+n^{*} \hat{Y}_{t}^{*}+\lambda_{Y, t}\right]+\frac{n^{*}}{1-\beta} V^{T}+O\left(\varepsilon^{3}\right)
$$

Notice that the expectational terms in $V^{T}$ are formed before policy is determined, while 
the expectational terms in other parts of (28) are formed after policy is determined. This expression can be used to show the impact of policy on home welfare. In particular, it can be compared to (23), which is the corresponding equation in the asset-trade-after-policy case. The important feature to note from (28) is that, because $0<n<1$, home income has a less than one-for-one impact on home consumption. Thus, unlike in the asset-tradeafter-policy case, a policy change which reduces the discounted value of home income has a less than one-for-one impact on the discounted value of home consumption.

The next section examines the welfare implications of the above results. Before proceeding, however, it is useful to summarise how the timing of asset trade affects the link between policy and consumption. Equation (25) shows that the choice of policy parameter potentially has two distinct effects that impact on expected consumption. The first is a flow effect, which operates directly via the term, $V$, in (25). The second is a valuation effect which arises via the capital gain term, $C G$, in (25). If asset trade in period 0 takes place after policy is decided, the capital gain term is not present (see equation (21)). In this case the choice of $\delta$ affects consumption only via the $V$ term. On the other hand, when asset trade takes place before policy is decided, equation (26) shows that, at the

time policy is determined, the choice of $\delta$ has no effect on $E_{0}\left[\hat{C}_{1}^{D}\right]$. This is because policy has an indirect effect on consumption via the capital gain term, $C G$. The capital gain effect exactly offsets the flow income effect. $C G$ is, in effect, the payoff to a portfolio which precisely hedges against policy changes. Note again that in equilibrium the capital gain term is zero, but it nevertheless has an important impact on the first derivative of $E_{0}\left[\hat{C}_{1}^{D}\right]$ with respect to $\delta$ and it thus affects the incentives facing the policymaker in the asset-trade-before-policy case.

\section{$5 \quad$ Welfare and equilibrium policy}

The implications for the welfare effects of policy can now be assessed by comparing equations (23) and (28). These two equations show the relationship between the discounted 
value of home income and the discounted value of home consumption. As already stressed, the main difference between these two equations is in the size of the coefficient on the first moment of home income. Equation (23) shows that this coefficient is unity in the asset-trade-after-policy case. This contrasts with equation (28) where the coefficient is $n$, which is less than unity. In other words, a monetary policy rule which depresses the expected level of home income will have a one-for-one negative impact on home consumption in the asset-trade-after-policy case, but will have a less than one-for-one impact on consumption in the asset-trade-before-policy case.

The differing impact of policy on consumption in the two cases obviously has implications for the incentives facing the policymaker. In particular it has implications for the trade-off between output (i.e. work effort) and consumption. If the output of home goods $(y)$ and home income $(Y)$ are positively related (as will be the case when $\theta>1$ ) then the policymaker faces a less favourable trade-off between output and consumption in the asset-trade-after-policy case than in the asset-trade-before-policy case. In the assettrade-after-policy case any policy which leads to a reduction in the expected level of home output and income will be penalised by a one-for-one reduction in home consumption. This tends to discourage the choice of a policy rule which depresses the expected level of home output. In the asset-trade-before-policy case the impact on consumption is less than one-for-one so that the policymaker faces an incentive to move the policy parameter in a direction which reduces the expected level of home output and income. In effect, part of the consumption impact of the policy choice is shifted on to foreign consumers.

\subsection{Numerical example}

The results derived above are now illustrated using a calibrated version of the model. For the purposes of this exercise the following parameter values are used:

$$
\beta=0.99, \gamma=0.75, \theta=4, \phi=8, \rho=1, \mu=2, \zeta=0.95, \sigma_{A}=0.01
$$


We report results for two values of $n$ : a large country case where $n=0.5$; and a small country case where $n=0.01$. The large country results are shown in Figure 4 and the small country results are shown in Figure 5. In the figures, welfare (in steady-state consumption units), consumption and output are measured in terms of the percentage deviation from a baseline stochastic solution where $\delta=0 .{ }^{17}$

\section{INSERT FIGURE 4 ABOUT HERE}

As discussed above, the main implications of the timing of asset trade operate via the impact of the policy parameter on the discounted value of expected home output and expected home consumption. Figure 4 plots these quantities, together with home welfare, for a range of values of $\delta$. The upper panel of Figure 4 shows these plots for the asset-trade-before policy case, while the lower panel shows the asset-trade-after-policy case.

Figure 4 shows that the welfare maximising value of $\delta$ differs between the two cases. Optimal $\delta$ is approximately 0.016 in the asset-trade-before-policy case and 0.0053 in the asset-trade-after-policy case. The underlying explanation for this difference is clear from the plots of consumption and output. The upper panel shows that, as $\delta$ increases, the discounted expected value of home output declines. This tends to raise home welfare (because it represents a fall in work effort). The discounted expected value of home consumption also declines as $\delta$ rises, but the decline in consumption is less than the decline in output. This reflects the cushioning effect of the capital gain in the assettrade-before-policy case. The decline in consumption tends to reduce home welfare, but (initially at least) this is not sufficient to offset the welfare benefit of lower work effort. The optimal value of $\delta$ is therefore relatively high.

These effects can be contrasted with the asset-trade-after-policy case shown in the lower panel of Figure 4. There it can be seen that the expected discounted value of home output also declines as $\delta$ is increased. But in this case the declining level of home output is closely matched by the decline in the expected discounted value of home consumption. The welfare benefit of lower work effort is almost exactly offset by the welfare cost of 
lower consumption. The optimal value of $\delta$ is therefore relatively low.

\section{INSERT FIGURE 5 ABOUT HERE}

Figure 5 shows the same set of comparisons for the small country example, where $n=0.01$. The lower panel of Figure 5 shows that the general shapes of the welfare, output and consumption relationships are similar to the large country example. The main difference between the small country and large country examples occurs in the asset-trade-before-policy case. The upper panel shows that, in this case, welfare is now convex in $\delta$ rather than concave (at least within the range of values of $\delta$ shown here). The explanation for this is evident from equation (28) and from the plot of consumption in the upper panel of Figure 5. Equation (28) shows that, when $n$ is very small, home country consumption becomes almost entirely insulated from the level of home country income. In terms of the upper panel of Figure 5, the relationship between consumption and $\delta$ is close to a horizontal straight line. This implies that, as $\delta$ increases, the positive welfare effect caused by the reduction of home output is not offset by any reduction in consumption. Welfare is therefore monotonically increasing in $\delta$ (within the range of $\delta$ shown here).

\subsection{Prior beliefs and equilibrium}

So far the analysis of the asset-trade-before-policy case has been based on the assumption that prior beliefs about the policy parameter, $\delta$, are fixed and exogenous. However, the full solution of the model requires the endogenous determination of these prior beliefs. Deriving this solution, however, is very straightforward.

Note from equations (13) and (28) that prior beliefs about $\delta$ only enter the model via the term $V^{T}$, which (from the point of view of the policymaker at the time policy is determined) is a constant. This constant will affect the equilibrium level of consumption, work-effort and output and will thus affect the equilibrium level of welfare. But, because $V^{T}$ does not depend on the actual choice of $\delta$, prior beliefs about $\delta$ have no impact on the first-order conditions of the policymaker's welfare maximisation problem. The 
policymaker's welfare maximising choice of $\delta$ is therefore independent of the prior beliefs about $\delta$ embodied in $V^{T}$. This confirms the assertion, illustrated in Figure 3, that the best response function of the monetary authority is horizontal.

\section{INSERT FIGURE 6 ABOUT HERE}

Figure 6 demonstrates some of the details of the determination of equilibrium for the numerical example discussed above. As in Figure 3, the prior belief about $\delta$, denoted $\delta^{T}$, is measured along the horizontal axis and the actual value of $\delta$ is measured on the vertical axis. The curves marked $\Omega_{1}$ to $\Omega_{5}$ are iso-welfare curves, i.e. loci of points on the figure which yield the same value of home country welfare. Welfare is increasing in a leftwards direction, so $\Omega_{5}$ represents higher welfare than $\Omega_{4}$, and so on for the other iso-welfare curves.

The iso-welfare curves can be used to trace out the best response function. For any given value of $\delta^{T}$, the policymaker's optimal choice of $\delta$ is the point of tangency between an iso-welfare curve and a vertical line drawn at the given value of $\delta^{T}$. These points of tangency trace out the horizontal best response function shown in Figure 6 . The equilibrium point for this particular numerical example is marked $B$. This yields an equilibrium value of $\delta$, denoted $\delta^{O}$, where $\delta^{O}=\delta^{T}=0.016$.

As previously explained, in equilibrium the capital gain at the time policy is determined is zero. Note however that the position of the best response function is tied down by the first-order condition of the monetary authority and the first-order condition takes into account the first derivative of the capital gain term with respect to the policy parameter. So the presence of the capital gain term affects the position of the best response function even though the capital gain is zero in equilibrium.

Figure 6 shows clearly that, for any value of $\delta^{T}$ not equal to $\delta^{O}$, say $\delta^{X}$, the policymaker can choose a value of $\delta$ on the best response function which yields higher welfare (i.e. is located on a superior iso-welfare curve) than choosing $\delta=\delta^{X}$.

Notice that Figure 6 can also be used to locate the equilibrium value of $\delta$ in the asset-trade-after-policy case. In the asset-trade-after-policy case it is true by definition 
that the actual and expected value of $\delta$ are always equal. This effectively implies that the policymaker is constrained to choose a point on the $45^{0}$ line. The optimal point on the $45^{0}$ line is a point of tangency between an iso-welfare curve and the $45^{0}$ line. This is marked point $A$ on the figure. This implies $\delta=0.0053$ for this numerical example, which corresponds to the optimal $\delta$ identified in the lower panel of Figure 4.

Figure 6 shows clearly that welfare at the equilibrium of the asset-trade-before-policy case (point $B$ ) will be lower than welfare at the asset-trade-after-policy case (point $A$ ). This follows because point $A$ is on a better iso-welfare function than point $B$. It is of course true that, if prior beliefs implied $\delta^{T}=0.0053$, the policymaker in the asset-tradebefore-policy case could achieve higher welfare at point $C$ on the best response function. But this point is not attainable in equilibrium because agents in asset markets would not rationally expect $\delta=0.0053$. The only rational expectations equilibrium in the assettrade-before-policy case is point $B$.

The small-country case illustrated in Figure 5 shows a case where equilibrium in the asset-trade-before-policy case is apparently not well-defined. In this case the welfare function is convex and there is no finite welfare maximising value of $\delta$.

Before concluding, it is useful briefly to consider the case where asset trade in period 0 occurs at exactly the same time as monetary policy is determined. Given the analysis described above, equilibrium in this case is very easy to derive. It is in fact identical to the equilibrium of the asset-trade-before-policy case. To see this note that, as stated above, the policymaker's optimal choice of $\delta$ for any value of $\delta^{T}$ is a constant, $\delta^{O}$. If agents in asset markets understand the policymaker's welfare maximisation problem then their best prediction of $\delta$ is $\delta^{O}$ regardless of whether asset trade takes place before or is simultaneous to the policy decision. Hence asset markets will set $\delta^{T}=\delta^{O}$ and the policymaker will set $\delta=\delta^{O}$, exactly as in the asset-trade-before-policy case. 


\section{Conclusion}

Using a standard dynamic general equilibrium model of an open economy, this paper has shown how the timing of asset trade relative to policy decisions can affect the welfare evaluation of policy. It is shown that, if asset trade in the initial period takes place before the announcement of the monetary policy rule, home consumers are effectively insured against the choice of policy rule. This allows the home country policymaker to choose a policy rule which reduces home country work effort in the knowledge that the impact on home country consumption is cushioned by portfolio returns at the time of the policy announcement. If, on the other hand, asset trade in the initial period takes place after the announcement of the policy rule, this insurance is not present and home consumers have to bear the full consumption consequences of a reduction in home output. The welfare incentives faced by the policymaker are significantly different between the two cases. In the asset-trade-before-policy case a welfare maximising policymaker has an incentive to choose a policy rule which depresses the expected level of home output. This incentive does not arise in the asset-trade-after-policy case. Numerical examples confirm that this can have a significant impact on the welfare maximising policy rule (particularly in the small economy example).

The current literature on monetary policy in open economies tends (implicitly) to focus on the asset-trade-before-policy case. The analysis reported above shows that this is not an innocuous assumption and demonstrates in detail how and why the timing of asset market trade matters. In itself, however, the analysis provides no definitive guidance on which assumption about asset market timing is most appropriate. From an empirical perspective, it is arguable that policy decisions are always made against a background where agents hold diversified portfolios. Policy announcements frequently give rise to asset price movements and therefore capital gains and losses. The asset-trade-beforepolicy case therefore has some claims to empirical relevance.

In Senay and Sutherland (2007), in the context of a static single-period model, we speculated that the asset-trade-after-policy case has more claim to empirical relevance 
because it appears to capture the fact that asset trade must, by definition, occur after policy announcements in a multi-period world. The current paper explicitly shows that, even when there is period-by-period asset trade, the crucial issue is the timing of asset trade in the period in which a policy announcement is made. The empirical relevance of the two approaches is therefore more finely balanced than suggested in Senay and Sutherland (2007).

Regardless of empirical considerations, from a theoretical perspective it seems unsatisfactory to judge the welfare effects of policy in a framework where the population of the country in question is implicitly insured against the potential adverse effects of policy. This paper shows that, when analysing the welfare effects of policy in open economies, it is important to acknowledge and understand the welfare incentives created by international financial markets. This is an issue which has, hitherto, received little attention in the related literature. 


\section{Appendix}

\section{Second-order terms}

The second-order term $\lambda_{B, t}$ which appears in equation (14) is defined as follows

$$
\lambda_{B, t}=\frac{1}{2} \hat{Y}_{t}^{2}-\frac{1}{2} \hat{C}_{t}^{2}+\hat{\alpha}_{t-1} \hat{r}_{x, t}+\frac{1}{\beta} \hat{W}_{t-1} \hat{r}_{2, t}
$$

where $\hat{\alpha}_{t-1}=\left(\alpha_{t-1}-\bar{\alpha}\right) /(\beta \bar{Y})$. Note that this expression contains a term in the firstorder deviation of gross portfolios from the non-stochastic steady state, $\hat{\alpha}_{t-1}$. Devereux and Sutherland (2010) explain how to derive a solution for $\hat{\alpha}_{t-1}$. This term, however, drops out of the analysis once the conditional expectations operator is applied, so an explicit solution is not required for the results reported above.

The second-order term $\lambda_{Y, t}$ in equation (16) is defined as follows

$$
\lambda_{Y, t}=\frac{1}{2} n n^{*}\left(\hat{Y}_{t}-\hat{Y}_{t}^{*}\right)^{2}
$$

The derivation of this expression (and a number of other expressions used above) is considerably simplified by noting that, at the level of a first-order approximation, equity trade ensures that $\hat{C}_{t}=\hat{C}_{t}^{*}+O\left(\varepsilon^{2}\right)$ for all $t$ and in all states of the world, regardless of the timing of asset trade in period 0 .

The second-order term $\lambda_{A, t}$ in equation (19) is defined as follows

$$
\lambda_{A, t}=\frac{1}{2}\left(\hat{Y}_{t}^{2}-\hat{Y}_{t}^{* 2}\right)+\frac{1}{n^{*}} \hat{\alpha}_{t-1} \hat{r}_{x, t}+\frac{1}{\beta n^{*}} \hat{W}_{t-1} \hat{r}_{2, t}
$$

The second-order term $\lambda_{C, t}$ in equation (23) is defined as follows

$$
\lambda_{C, t}=\frac{1}{2} n^{* 2}\left(\hat{Y}_{t}-\hat{Y}_{t}^{*}\right)^{2}+n^{*}(1-\rho)\left(\hat{Y}_{t}-\hat{Y}_{t}^{*}\right)\left(n \hat{Y}_{t}+n^{*} \hat{Y}_{t}^{*}\right)
$$




\section{Asset holdings and the budget constraint}

In the text, we focus on a case where assets are defined to be in zero net supply. Here we show that a more conventional model with trade in equities which are in positive net supply may easily be transformed into the algebra of zero net supply used in the text. To see this in the context of the example model, assume that, instead of receiving income from production, all income comes in the form of returns on holdings of home and foreign equity. Let $\omega_{1, t}$ and $\omega_{1, t}^{*}$ represent the home and foreign share of home equity, and normalize so that the total supply of home equity is unity. Likewise, let $\omega_{2, t}$ and $\omega_{2, t}^{*}$ represent the home and foreign holdings of foreign equity, with total supply again normalized to unity. Then in an economy where there is asset trade only in the two equities, the home country faces a budget constraint given by:

$$
Z_{t} \omega_{1, t}+Z_{t}^{*} \omega_{2, t}=\left(Z_{t}+Y_{t}\right) \omega_{1, t-1}+\left(Z_{t}^{*}+Y_{t}^{*}\right) \omega_{2, t-1}-C_{t}
$$

where, as before, $Z_{t}$ and $Z_{t}^{*}$ are equity prices. The equity market clearing conditions are now

$$
\omega_{1, t}+\omega_{1, t}^{*}=1, \quad \omega_{2, t}+\omega_{2, t}^{*}=1
$$

It is easy to show that (30) may be transformed into the budget constraint used in the text, where assets are defined to be in zero net supply. To see this, re-write (30) in the form

$$
Z_{t}\left(\omega_{1, t}-1\right)+Z_{t}^{*} \omega_{2, t}=\frac{Z_{t}+Y_{t}}{Z_{t-1}} Z_{t-1}\left(\omega_{1, t-1}-1\right)+\frac{Z_{t}^{*}+Y_{t}^{*}}{Z_{t-1}^{*}} Z_{t-1}^{*} \omega_{2, t-1}+Y_{t}-C_{t}
$$

Now redefining $\alpha_{1, t}=Z_{t}\left(\omega_{1, t-1}-1\right)$ as external holdings of the home asset and $\alpha_{2, t}=$ $Z_{t}^{*} \omega_{2, t}$ as external holdings of the foreign asset, we arrive at

$$
\alpha_{1, t}+\alpha_{2, t}=\frac{Z_{t}+Y_{t}}{Z_{t-1}} \alpha_{1, t-1}+\frac{Z_{t}^{*}+Y_{t}^{*}}{Z_{t-1}^{*}} \alpha_{2, t-1}+Y_{t}-C_{t}
$$


which, given the definitions of $r_{1, t}$ and $r_{2, t}$, is identical to (6). Thus, the model where assets are in positive net supply is transformed into a model where the defined assets are in zero net supply.

\section{Derivation of equation (22)}

Substituting $E_{0}\left[\hat{r}_{x, t+1}\right]=R+O\left(\varepsilon^{3}\right)$ into (19) yields

$$
\begin{aligned}
E_{0}\left[\hat{C}_{1}^{D}\right]= & (1-\beta)\left(E_{0}\left[\hat{Y}_{1}-\hat{Y}_{1}^{*}\right]+\frac{1}{n^{*}} \tilde{\alpha} R+E_{0}\left[\lambda_{A, 1}\right]\right) \\
& +(1-\beta) \sum_{t=2}^{\infty} \beta^{t-1}\left(E_{0}\left[\hat{Y}_{t}-\hat{Y}_{t}^{*}\right]+\frac{1}{n^{*}} \tilde{\alpha} R+E_{0}\left[\lambda_{A, t}\right]\right)+O\left(\varepsilon^{3}\right)
\end{aligned}
$$

which can be simplified to yield

$$
E_{0}\left[\hat{C}_{1}^{D}\right]=(1-\beta) \sum_{t=1}^{\infty} \beta^{t-1}\left(E_{0}\left[\hat{Y}_{t}-\hat{Y}_{t}^{*}\right]+\frac{1}{n^{*}} \tilde{\alpha} R+E_{0}\left[\lambda_{A, t}\right]\right)+O\left(\varepsilon^{3}\right)
$$

Note that $R$ and $\lambda_{A}$ contain only second-order terms and can thus be evaluated using first-order accurate expressions for $\hat{C}, \hat{C}^{*}, \hat{r}_{1}, \hat{r}_{2}$ and $\hat{W}$. Furthermore, it is possible to obtain expressions for $\hat{C}, \hat{C}^{*}, \hat{r}_{1}, \hat{r}_{2}$ and $\hat{W}$ in terms of $\hat{Y}$ and $\hat{Y}^{*}$ and thus express $R$ and $\lambda_{A}$ in terms of the second moments of $\hat{Y}$ and $\hat{Y}^{*}$. After much further algebra it is possible to show that

$$
\begin{aligned}
& \sum_{t=1}^{\infty} \beta^{t-1}\left(\frac{1}{n^{*}} \tilde{\alpha} R+E_{0}\left[\lambda_{A, t}\right]\right)= \\
& \quad \sum_{t=1}^{\infty} \beta^{t-1} \frac{1}{2} E_{0}\left[(1-2 n \rho) \hat{Y}_{t}^{2}-\left(1-2 n^{*} \rho\right) \hat{Y}_{t}^{* 2}-2\left(n^{*}-n\right) \rho \hat{Y}_{t} \hat{Y}_{t}^{*}\right]+O\left(\varepsilon^{3}\right)
\end{aligned}
$$

so

$$
E_{0}\left[\hat{C}_{1}^{D}\right]=(1-\beta) \sum_{t=1}^{\infty} \beta^{t-1}\left(E_{0}\left[\hat{Y}_{t}-\hat{Y}_{t}^{*}\right]+\lambda_{V, t}\right)+O\left(\varepsilon^{3}\right)
$$

where

$$
\lambda_{V, t}=\frac{1}{2} E_{0}\left[(1-2 n \rho) \hat{Y}_{t}^{2}-\left(1-2 n^{*} \rho\right) \hat{Y}_{t}^{* 2}-2\left(n^{*}-n\right) \rho \hat{Y}_{t} \hat{Y}_{t}^{*}\right]
$$




\section{Equity prices}

The returns on home and foreign equities are given by $r_{1, t}=X_{t} / Z_{t-1}$ and $r_{2, t}=X_{t}^{*} / Z_{t-1}^{*}$,

where, for convenience, equity payoffs are defined as $X_{t}=Y_{t}+Z_{t}$ and $X_{t}^{*}=Y_{t}^{*}+Z_{t}^{*}$. Second-order approximation of these relationships imply

$$
\begin{aligned}
& \hat{r}_{1, t}=\hat{X}_{t}-\hat{Z}_{t-1}+\frac{1}{2} \hat{r}_{1, t}^{2}+O\left(\varepsilon^{3}\right) \\
& \hat{r}_{2, t}=\hat{X}_{t}^{*}-\hat{Z}_{t-1}^{*}+\frac{1}{2} \hat{r}_{2, t}^{2}+O\left(\varepsilon^{3}\right)
\end{aligned}
$$

and

$$
\begin{aligned}
& \hat{X}_{t}=(1-\beta) \hat{Y}_{t}+\beta \hat{Z}_{t}+\lambda_{X, t}+O\left(\varepsilon^{3}\right) \\
& \hat{X}_{t}^{*}=(1-\beta) \hat{Y}_{t}^{*}+\beta \hat{Z}_{t}^{*}+\lambda_{X^{*}, t}+O\left(\varepsilon^{3}\right)
\end{aligned}
$$

where

$$
\begin{aligned}
& \lambda_{X, t}=\frac{1}{2}(1-\beta) \hat{Y}_{t}^{2}+\frac{1}{2} \beta \hat{Z}_{t}^{2}-\frac{1}{2} \hat{X}_{t}^{2} \\
& \lambda_{X^{*}, t}=\frac{1}{2}(1-\beta) \hat{Y}_{t}^{* 2}+\frac{1}{2} \beta \hat{Z}_{t}^{* 2}-\frac{1}{2} \hat{X}_{t}^{* 2}
\end{aligned}
$$

Using (33), (34) and the fact that $R=E_{t}\left[\hat{r}_{1, t+1}-\hat{r}_{2, t+1}\right]$, it follows that

$$
\begin{aligned}
\hat{Z}_{t}-\hat{Z}_{t}^{*}= & \beta E_{t}\left(\hat{Z}_{t+1}-\hat{Z}_{t+1}^{*}\right) \\
& +E_{t}\left[(1-\beta)\left(\hat{Y}_{t+1}-\hat{Y}_{t+1}^{*}\right)+\frac{1}{2}\left(\hat{r}_{1, t+1}^{2}-\hat{r}_{2, t+1}^{2}\right)+\left(\lambda_{X, t+1}-\lambda_{X^{*}, t+1}\right)\right] \\
& -R+O\left(\varepsilon^{3}\right)
\end{aligned}
$$

and thus the difference between home and foreign equity prices can be written as follows

$$
\hat{Z}_{t}-\hat{Z}_{t}^{*}=\sum_{i=1}^{\infty} \beta^{i-1}\left\{E_{t}\left[(1-\beta)\left(\hat{Y}_{t+i}-\hat{Y}_{t+i}^{*}\right)+\lambda_{E, t+i}\right]-R\right\}+O\left(\varepsilon^{3}\right)
$$

where

$$
\lambda_{E, t}=\frac{1}{2}\left(\hat{r}_{1, t}^{2}-\hat{r}_{2, t}^{2}\right)+\lambda_{X, t}-\lambda_{X^{*}, t}
$$


After some rearrangement $\lambda_{E, t}$ can be written as follows

$$
\begin{aligned}
\lambda_{E, t}= & \frac{1}{2}(1-\beta)\left(\hat{Y}_{t}^{2}-\hat{Y}_{t}^{* 2}\right)+\frac{1}{2} \beta\left(\hat{Z}_{t}^{2}-\hat{Z}_{t}^{* 2}\right) \\
& -\frac{1}{2}\left(\hat{Z}_{t-1}^{2}-\hat{Z}_{t-1}^{* 2}\right)-\left(\hat{r}_{1, t} \hat{Z}_{t-1}-\hat{r}_{2, t} \hat{Z}_{t-1}^{*}\right)
\end{aligned}
$$

The capital gain term, $C G=\left(\hat{Z}_{0}-\hat{Z}_{0}^{*}\right)-\left(\hat{Z}_{0}^{T}-\hat{Z}_{0}^{* T}\right)$, is thus

$$
\begin{aligned}
C G=\sum_{t=1}^{\infty} \beta^{t-1}\left\{(1-\beta)\left(E_{0}\left[\hat{Y}_{t}-\hat{Y}_{t}^{*}\right]-E_{0}^{T}\left[\hat{Y}_{t}-\hat{Y}_{t}^{*}\right]\right)\right. \\
\left.+\left(E_{0}\left[\lambda_{E, t}\right]-E_{0}^{T}\left[\lambda_{E, t}\right]\right)-\left(R-R^{T}\right)\right\}+O\left(\varepsilon^{3}\right)
\end{aligned}
$$

\section{Derivation of equation (27)}

Equation (37) can be substituted into (25) and simplified (using $\tilde{\alpha}=-n^{*} /(1-\beta)$ ) to yield

$$
\begin{aligned}
E_{0}\left[\hat{C}_{1}^{D}\right]= & (1-\beta) \sum_{t=1}^{\infty} \beta^{t-1}\left\{E_{0}^{T}\left[\hat{Y}_{t}-\hat{Y}_{t}^{*}\right]+\frac{1}{n^{*}} \tilde{\alpha}\left(E_{0}\left[\lambda_{E, t}\right]-E_{0}^{T}\left[\lambda_{E, t}\right]\right)+\frac{1}{n^{*}} \tilde{\alpha} R^{T}\right\} \\
& +(1-\beta) \sum_{t=1}^{\infty} \beta^{t-1} E_{0}\left[\lambda_{A, t}\right]+O\left(\varepsilon^{3}\right)
\end{aligned}
$$

Note that $\lambda_{E}$ and $\lambda_{A}$ contain only second-order terms and can thus be evaluated using first-order accurate expressions for $\hat{C}, \hat{C}^{*}, \hat{r}_{1}, \hat{r}_{2}$ and $\hat{W}$. As above, it is possible to obtain expressions for $\hat{C}, \hat{C}^{*}, \hat{r}_{1}, \hat{r}_{2}$ and $\hat{W}$ in terms of $\hat{Y}$ and $\hat{Y}^{*}$ and thus express $\lambda_{E}$ and $\lambda_{A}$ in terms of the second moments of $\hat{Y}$ and $\hat{Y}^{*}$. After further algebra it can be shown that

$$
\sum_{t=1}^{\infty} \beta^{t-1} E_{0}\left[\frac{1}{n^{*}} \tilde{\alpha} \lambda_{E, t}+\lambda_{A, t}\right]=0+O\left(\varepsilon^{3}\right)
$$

so

$$
E_{0}\left[\hat{C}_{1}^{D}\right]=(1-\beta) \sum_{t=1}^{\infty} \beta^{t-1}\left(E_{0}^{T}\left[\hat{Y}_{t}-\hat{Y}_{t}^{*}\right]+\lambda_{V, t}^{T}\right)+O\left(\varepsilon^{3}\right)
$$


where

$$
\lambda_{V, t}^{T}=\frac{1}{2} E_{0}^{T}\left[(1-2 n \rho) \hat{Y}_{t}^{2}-\left(1-2 n^{*} \rho\right) \hat{Y}_{t}^{* 2}-2\left(n^{*}-n\right) \rho \hat{Y}_{t} \hat{Y}_{t}^{*}\right]
$$




\section{Notes}

1. See, for instance, Gali and Monacelli (2005), Devereux and Engel (2003), Benigno and Benigno (2006), Pappa (2004), Faia and Monacelli (2008) and De Paoli (2009a 2009b). Some significant contributions to the open economy literature, however, are not based on trade in Arrow-Debreu assets. For instance, Clarida, Gali and Gertler (2002) and Corsetti and Pesenti (2005) assume a unit elasticity of international trade. This implies that financial market structure is irrelevant. Obstfeld and Rogoff (1995) and Kollmann (2002) assume that international financial trade is confined to non-contingent bonds.

2. Note that asset market timing is only relevant for welfare evaluation from the point of view of national policymakers. When the global welfare effects of policy are analysed from the point of view of a global policymaker, the spillover generated by asset trade is fully internalised by the policymaker regardless of the timing of asset trade. The timing of asset trade therefore has no impact on the incentives faced by a global policymaker.

3. In a rational expectations equilibrium the actual realised capital gain is always zero. However, it is the impact on the policymaker's incentives that is created by the potential capital gain which is important for generating the difference between the asset-trade-before-policy case and the asset-trade-after-policy case.

4. In an analysis of optimal capital taxation in a small open economy Schmitt-Grohe and Uribe (2003) also discuss an issue related to the timing of asset trade. Rather than focusing on the timing of asset trade per se, they frame the problem in terms of the presence or absence of Arrow-Debreu securities which are specifically contingent on the decisions of the policymaker. Wagner (2007) has analysed the role of international risk sharing in distorting the incentives faced by national policymakers. However, Wagner does not analyse the implications of the timing of asset trade. Devereux and Engel (2003) do explicitly consider asset market timing in relation to optimal monetary policy in an open economy. But asset markets have a very limited 
role in their model because they impose a unit elasticity of substitution between goods produced in different countries. Devereux and Engel therefore find that asset market timing has no implications for any of their results.

5. We assume that policy is represented by a credible once-and-for-all decision about a policy rule. An alternative approach would be to assume that policy is re-optimised period by period. This creates a dynamic game between the policymaker and traders in asset markets. The equilibrium of this dynamic game will depend on the timing of asset trade relative to the policy decision with-in each period. We focus on the case where policy is a once-and-for-all decision because this corresponds more closely to the standard assumption in the existing literature on monetary policy in open economies. The alternative assumption (where policy is re-optimised period by period) is likely to be an interesting topic for further research.

6. In the model used below, equity trade is sufficient to support full risk sharing (for a given setting of monetary policy). Our asset-trade-before-policy case corresponds precisely to the Arrow-Debreu case which is the standard assumption in the literature. But the same issues (about the timing of asset trade) also arise when there are not sufficient assets to support full risk sharing. In cases such as this there is not full insurance, but the timing of asset trade affects the degree to which there is insurance against policy changes, and this insurance will work through a capital gain valuation effect in the initial period. See Devereux and Sutherland (2008) for an example of how the setting of monetary policy can affect portfolio allocation in a model where markets are incomplete. Devereux and Sutherland (2008) do not explicitly analyse the welfare effects of policy, nor do they consider issues related to the timing of asset trade.

7. We adopt the notational convention that $\alpha_{1}$ and $\alpha_{2}$ represent external holdings of equities. That is, $\alpha_{1}$ is the value of claims on home output sold by home households to foreign households, and $\alpha_{2}$ is the value of claims on foreign output sold by foreign households to home households. An alternative notational convention is to measure 
portfolio positions in terms of the total (internal plus external) holdings of assets. Our choice of notational convention involves no loss of generality and proves to be particularly convenient for deriving our results. See the Appendix for an explanation of the link between the two notational conventions.

8. For the purposes of this paper, a rule of the form given in (11) is nevertheless a reasonable choice as a benchmark example because it is known that optimal policy approximately takes this form in the context of a closed economy model analogous to the model outlined above (see for instance Woodford, 2003).

9. Note that in the asset-trade-after-policy case it is important that households do not hold any gross portfolio positions at the time of the policy announcement. "Asset prices" implicitly respond to the policy announcement, but, in the absence of any initial gross positions, this has no impact on $N F A$.

10. The interpretation of the interaction between the asset market and the policymaker as a game is however not fully satisfactory because the asset market is not a single agent that acts strategically, but is rather a mechanism where asset prices are determined via trade amongst a large number of atomistic agents who have rational expectations of future policy actions. In the analysis below we therefore do not formally pursue the game-theoretic interpretation of equilibrium.

11. Note that $\hat{\Omega} \equiv(1-\beta)(\Omega-\bar{\Omega}) \bar{C}^{\rho-1}$. By writing welfare in this form, $\hat{\Omega}$ can be interpreted in terms of "steady-state consumption units".

12. The policy parameter $\delta$ affects the equilibrium variance of output and thus the variance of the realised return on home equities. In equilibrium this affects the risk premium on home equities. Likewise, the variance of output affects optimal labour supply because households are risk averse (i.e. a higher variance of output reduces equilibrium work effort).

13. Strictly speaking, it is not necessary to use the Devereux and Sutherland method to derive a solution for $\tilde{\alpha}$. The financial structure in the above model implies that full consumption risk sharing (against shocks to $A$ ) is possible. Equilibrium gross 
portfolio positions can therefore simply be backed-out from a solution of the model where income pooling is imposed. This approach yields the same result as the Devereux and Sutherland method.

14. See Devereux and Sutherland (2008) for a more detailed derivation of this expression.

15. Note that we maintain the assumption that asset trade only actually takes place at the start of period 1. We are using the hypothetical re-opening of asset markets at the time of the policy announcement purely as a device for calculating the impact of the policy announcement on asset prices.

16. As noted in the introduction, in the existing literature it is typically stated that complete international risk sharing implies a relationship of the form $U_{C^{*}} / U_{C}=k\left(S P^{*} / P\right)$, where $U_{C}$ and $U_{C^{*}}$ are home and foreign marginal utilities of consumption and $k$ is an exogenous constant. In the context of the model of this paper, $U_{C}=C^{-\rho}, U_{C^{*}}=C^{*-\rho}$ and $S P^{*} / P=1$, so equation (26), which shows that $E_{0}\left[\hat{C}_{1}^{D}\right]$ is exogenous and constant in the asset-trade-before-policy case, is consistent with the assumption that $k$ is exogenous and constant. On the other hand, in the asset-trade-after-policy case, equation (25) shows that $E_{0}\left[\hat{C}_{1}^{D}\right]$ depends on the policymaker's choice of policy parameter. The asset-trade-after-policy case therefore implies that $k$ is endogenous and depends on policy choices.

17. In the asset-trade-before-policy case, the model is solved while imposing equation (26). The solution in the asset-trade-after-policy case requires that equation (21) is imposed. 


\section{References}

Benigno, Gianluca and Pierpaolo Benigno (2006) Designing targeting rules for international monetary policy cooperation. Journal of Monetary Economics 53, 473-506.

Calvo, Guillermo (1983) Staggered prices in a utility-maximising framework. Journal of Monetary Economics 12, 383-398.

Clarida, Richard, Jordi Gali and Mark Gertler (2002) A simple framework for international monetary policy analysis. Journal of Monetary Economics 49, 879-904.

Corsetti, Giancarlo and Paolo Pesenti (2005) International dimensions of optimal monetary policy. Journal of Monetary Economics 52, 281-305.

De Paoli, Bianca (2009a) Monetary policy and welfare in a small open economy. Journal of International Economics 77, 11-22.

De Paoli, Bianca (2009b) Monetary policy under alternative asset market structures: the case of a small open economy. Journal of Money, Credit and Banking 41, 1301-1330.

Devereux, Michael B. and Charles Engel (2003) Monetary policy in the open economy revisited: price setting and exchange-rate flexibility. Review of Economic Studies 70, 765-783.

Devereux, Michael B. and Alan Sutherland (2008) Financial globalization and monetary policy. Journal of Monetary Economics 55, 1363-1375.

Devereux, Michael B.and Alan Sutherland (2010) Country portfolio dynamics. Journal of Economic Dynamics and Control. 34, 1325-1342.

Devereux, Michael B.and Alan Sutherland (2011) Country portfolios in open economy macro models. Journal of the European Economic Association, 9, 337-369.

Faia, Ester and Tommaso Monacelli (2008).Optimal monetary policy in a small open economy with home bias. Journal of Money, Credit and Banking 40, 721-750. 
Gali, Jordi and Tommaso Monacelli (2005) Monetary policy and exchange rate volatility in a small open economy. Review of Economic Studies 72, 707-734.

Kollmann, Robert (2002) Monetary policy rules in the open economy: effects on welfare and business cycles. Journal of Monetary Economics 49, 989-1015.

Obstfeld, Maurice and Kenneth Rogoff (1995) Exchange rate dynamics redux. Journal of Political Economy 103, 624-660.

Pappa, Evi (2004) Should the Fed and the ECB cooperate? Optimal monetary policy in a two-country world. Journal of Monetary Economics 51, 753-779.

Schmitt-Grohé, Stephanie and Martin Uribe (2003) Anticipated Ramsey reforms and the uniform taxation principle: the role of international financial markets ECB Working Paper Series No. 210.

Senay, Ozge and Alan Sutherland (2007) Optimal monetary policy and the timing of asset trade in open economies. Economics Letters 95, 297-302.

Tille, Cedric and Eric van Wincoop (2010) International capital flows. Journal of International Economics 80, 157-175.

Wagner, Wolf (2007) International risk sharing and governmental moral hazard. Open Economies Review 18, 577-598.

Woodford, Michael (2003) Interest and Prices: Foundations of a Theory of Monetary Policy, Princeton: Princeton University Press. 
Figure 1: Time line - asset trade before policy

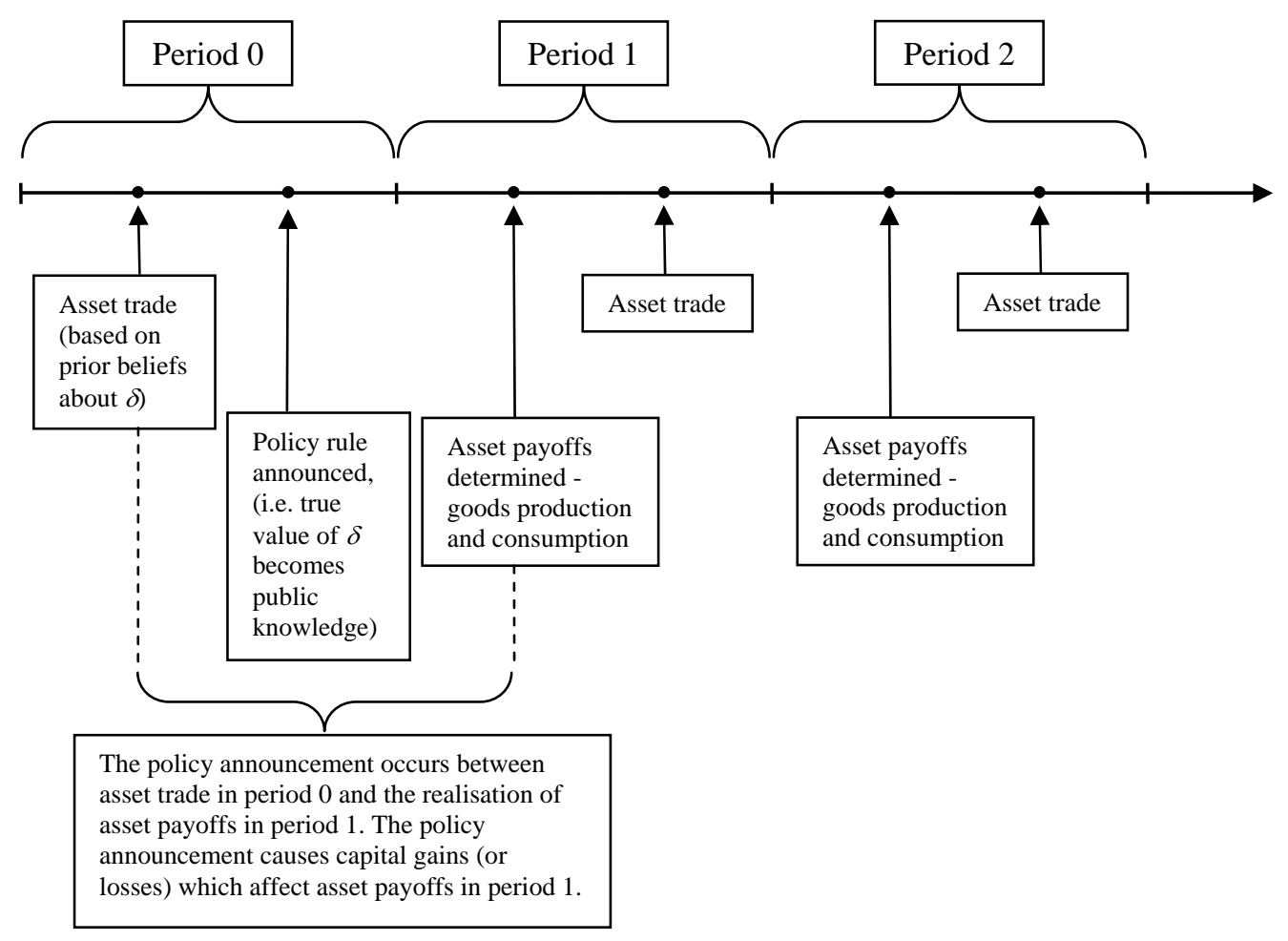


Figure 2: Time line - asset trade after policy

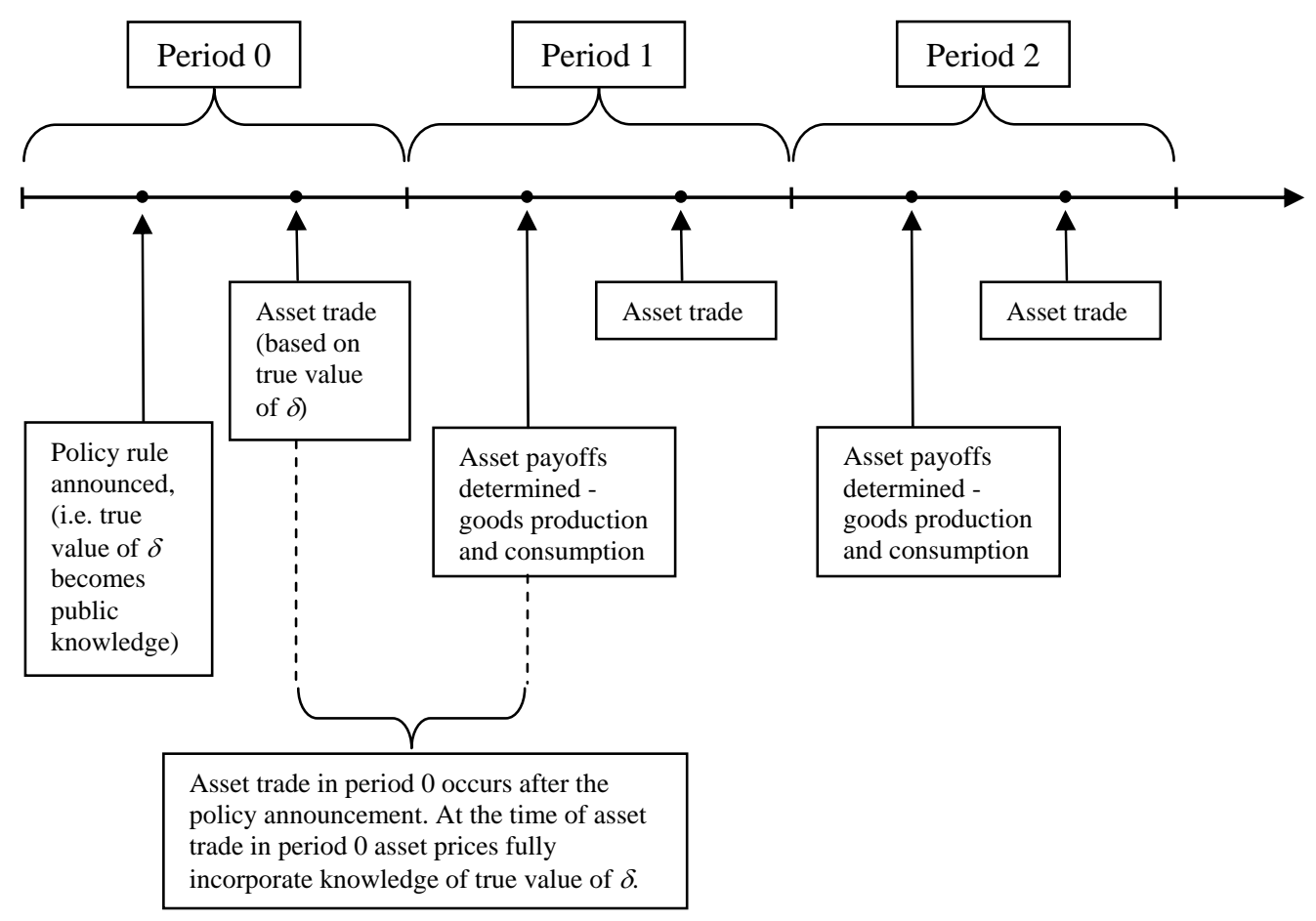


Figure 3: Equilibrium when asset trade takes before policy.

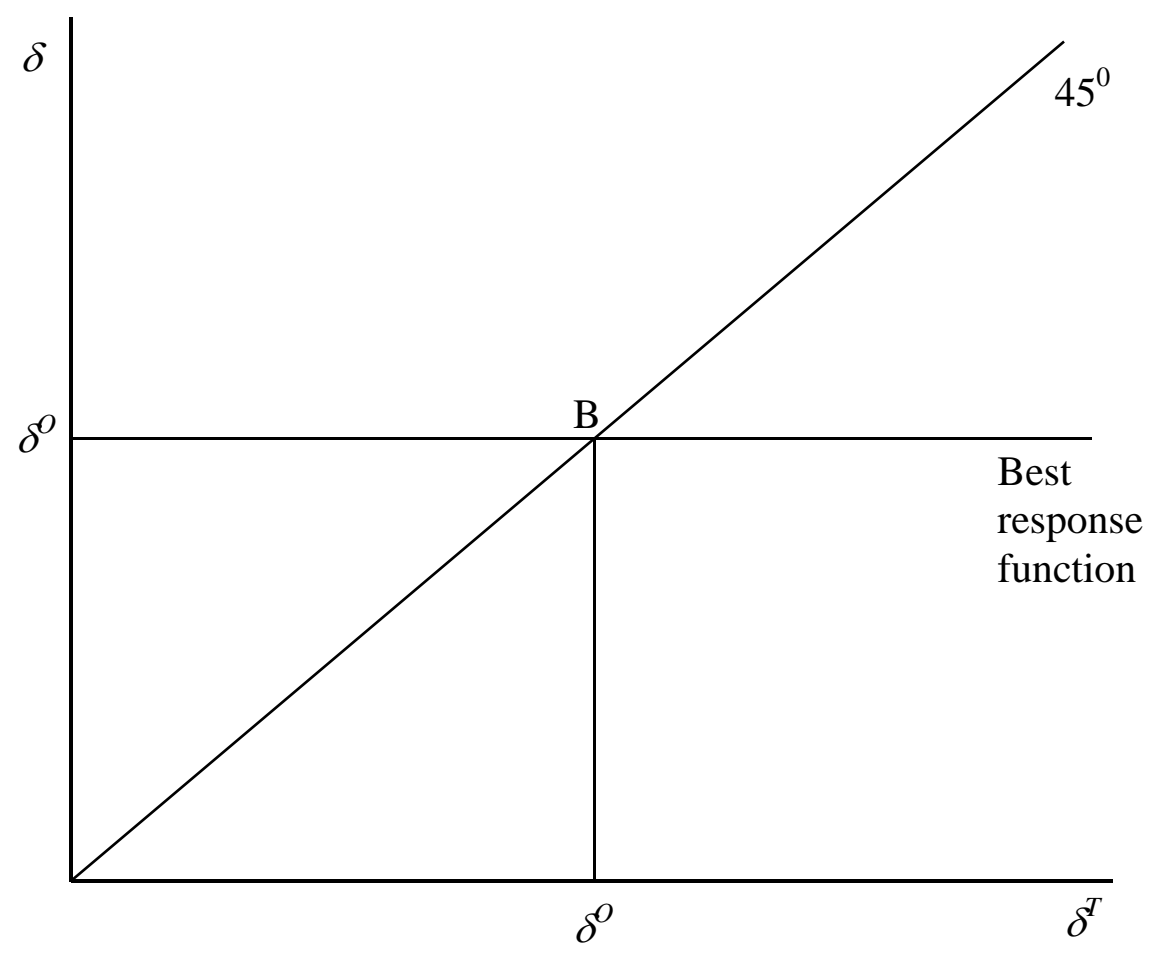


Figure 4: Large Country Example
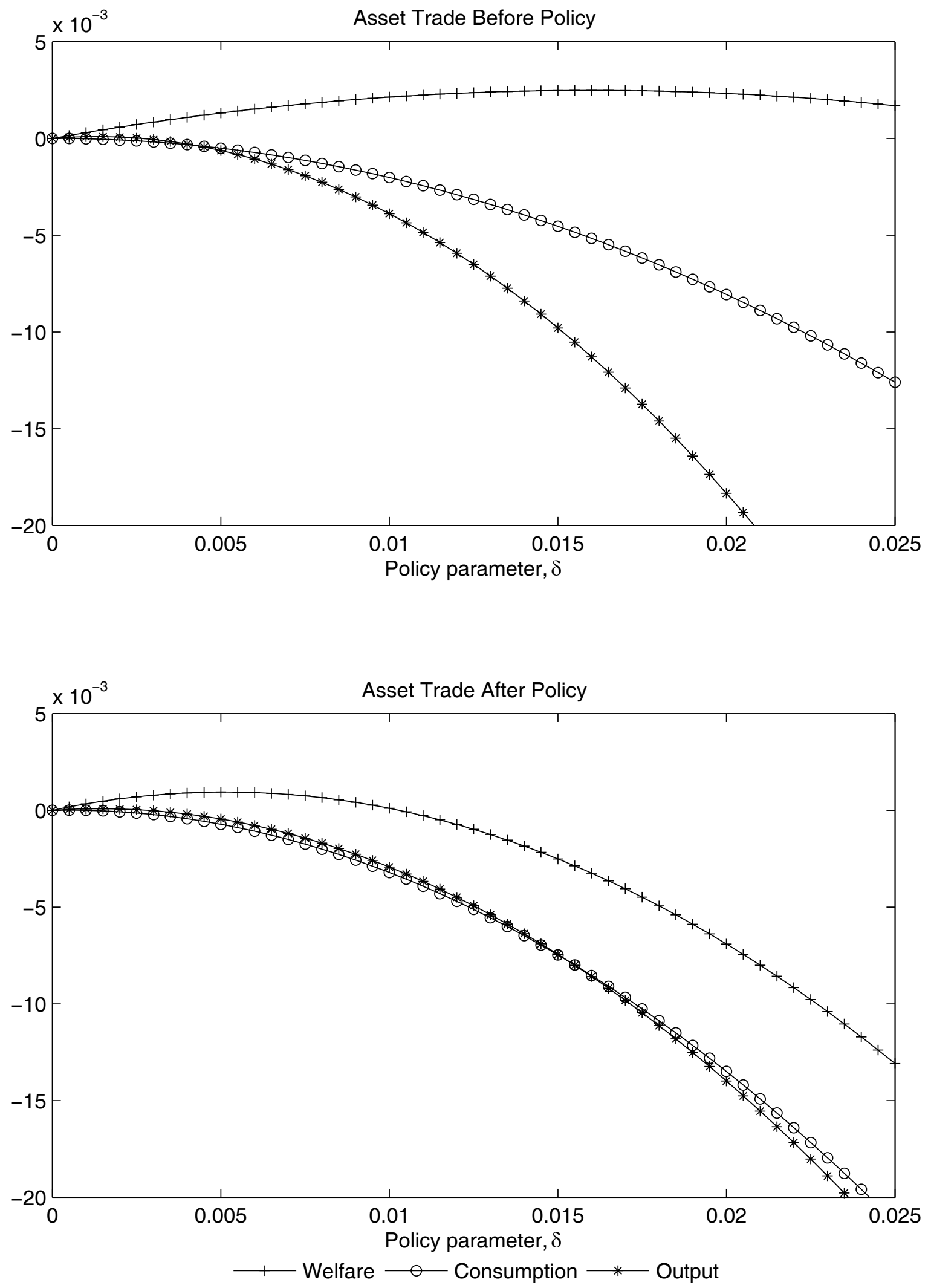
Figure 5: Small Country Example
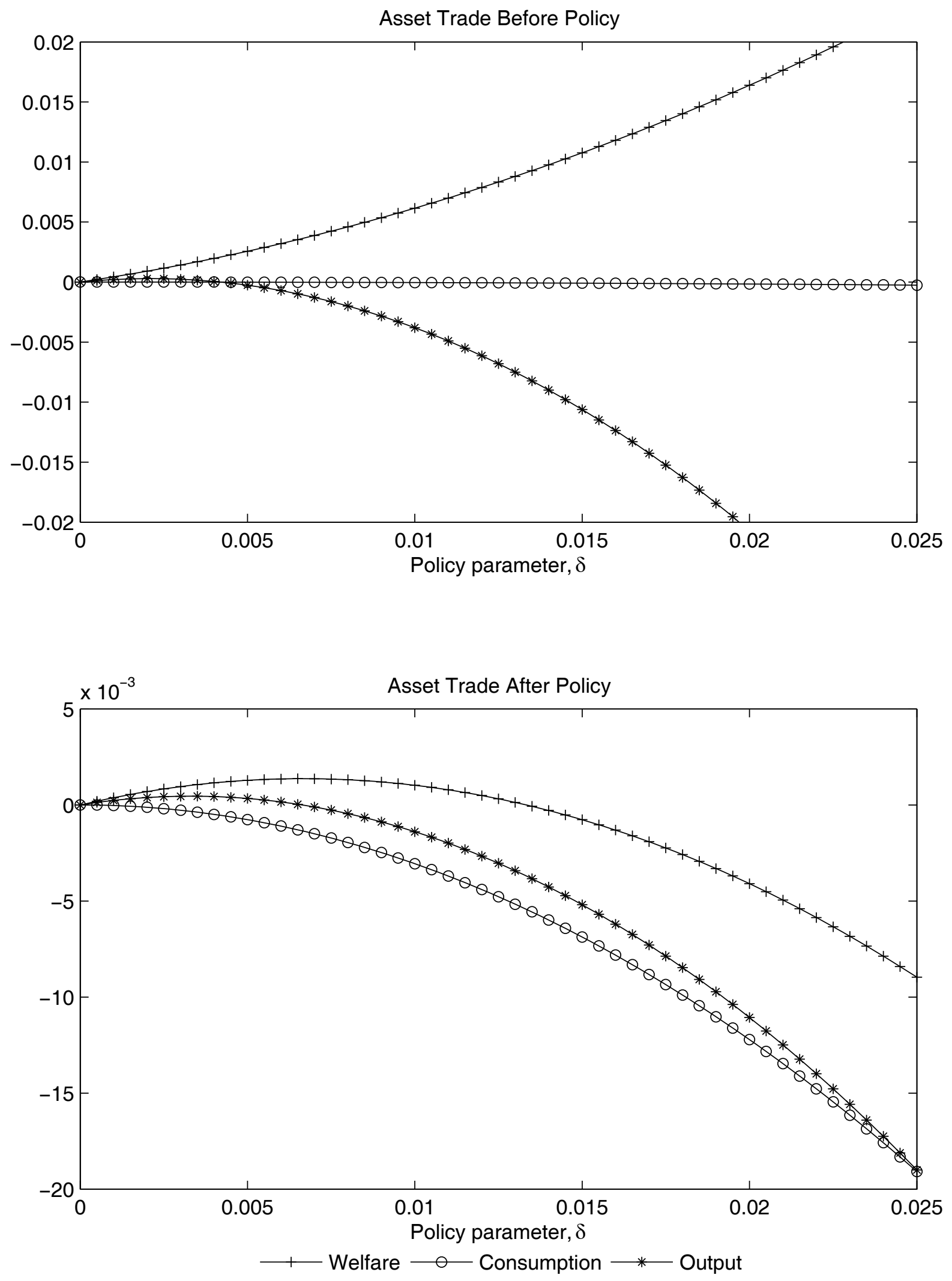
Figure 6: Equilibrium $\delta$ and welfare

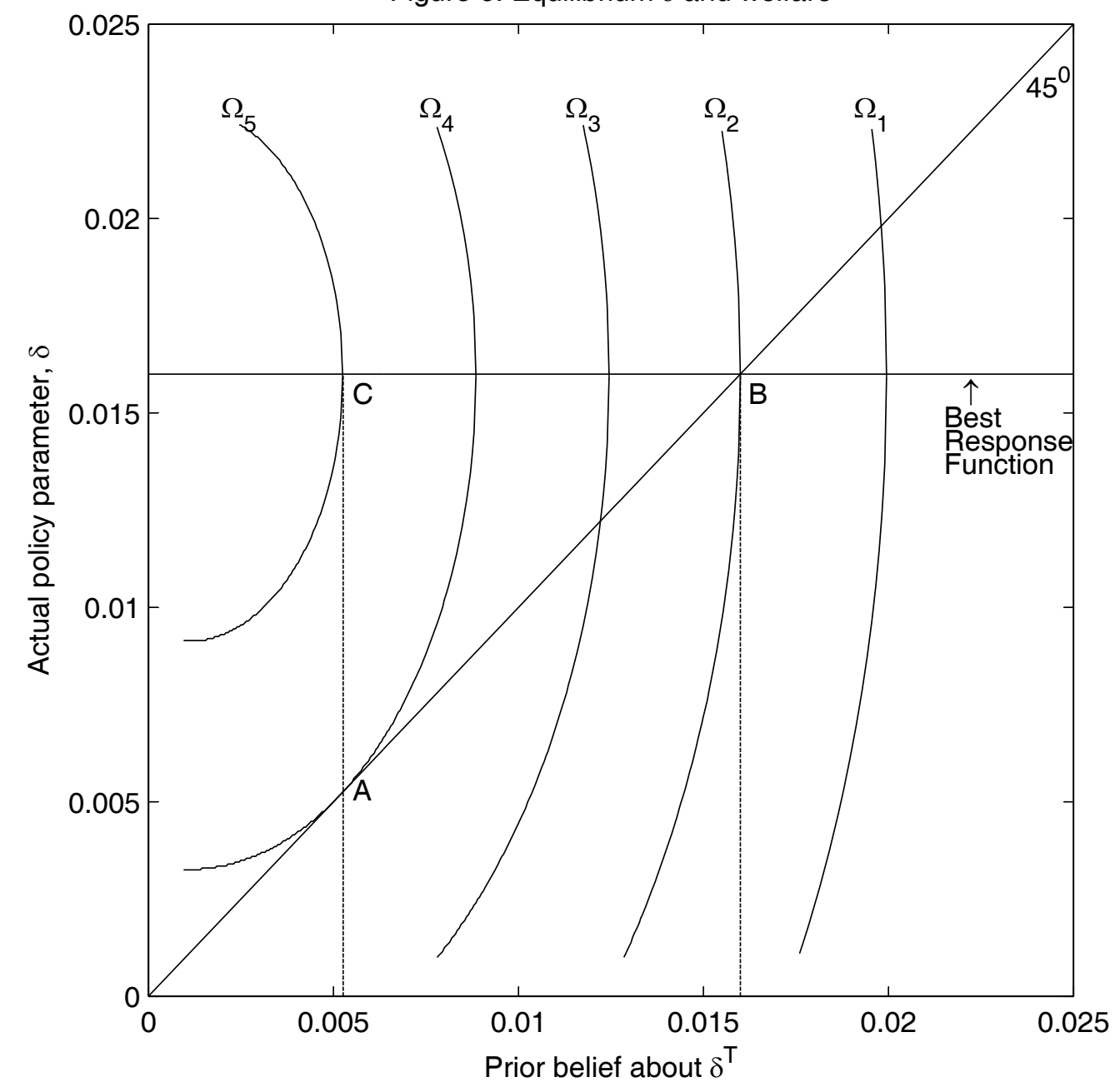

